\title{
Lessons from community-based distribution of family planning in
} Africa

\author{
James F. Phillips \\ Population Council \\ Wendy L. Greene \\ Elizabeth F. Jackson \\ Population Council
}

Follow this and additional works at: https://knowledgecommons.popcouncil.org/departments_sbsr-pgy

Part of the Family, Life Course, and Society Commons, and the International Public Health Commons How does access to this work benefit you? Let us know!

\section{Recommended Citation}

Phillips, James F., Wendy L. Greene, and Elizabeth F. Jackson. 1999. "Lessons from community-based distribution of family planning in Africa," Policy Research Division Working Paper no. 121. New York: Population Council. 


\title{
Lessons from Community-based D istribution of Family Planning in Africa
}

\author{
James F. Phillips \\ Wendy L. Greene \\ Elizabeth F. Jackson
}

1999 No. 121 


\title{
Lessons from Community-based Distribution of Family Planning in Africa
}

\author{
James F. Phillips \\ Wendy L. Greene \\ Elizabeth F. Jackson
}

James F. Phillips is Senior Associate and Elizabeth F. Jackson is Research Assistant, Policy Research Division, Population Council. Wendy L. Greene is a graduate student at the University of North Carolina at Chapel Hill School of Law. A previous version of this paper was presented at the International Union for the Scientific Study of Population Seminar, Reproductive Change in Sub-Saharan Africa, in Nairobi, Kenya, 2-4 November 1998. A previous version was prepared for the Population Council Africa Operations Research and Technical Assistance Project (OR/TA). The OR/TA Project is funded by the United States Agency for International Development, Contract Number DPE-3030-Z-00-8065-00. The authors gratefully acknowledge the helpful comments of Martin Brockerhoff, Barbara Mensch, Ian Askew, James Foreit, and Eugene Weiss, on previous drafts. 


\begin{abstract}
This paper reviews findings and experiences from efforts to implement community-based family planning services in sub-Saharan Africa. Although research suggests that community-based service delivery can contribute to contraceptive use, the magnitude of impact is often in doubt or is considerably less than was observed in similar projects in Asia in the 1970s and 1980s. Reasons for the constrained impact of community-based family planning in Africa are reviewed and assumptions about the efficacy and mechanism of community-based distribution (CBD) are discussed. Whereas several contrasting approaches to $\mathrm{CBD}$ have been tried, little is known about the relative merits of alternative $\mathrm{CBD}$ approaches.
\end{abstract}

This material may not be reproduced in any form without written permission from the authors. 
Efforts to improve the acceptability and efficacy of family planning programs often focus on developing convenient, nonclinical community-based services. Experience of a variety of experimental projects in Asia has shown that nonclinical access to contraceptives can improve the quality, acceptability, and impact of family planning programs. This experience, in turn, has led to a proliferation of large-scale programs in nonclinical family planning service delivery throughout the world. Widespread commitment to expanding nonclinical family planning programs is based on assumptions about the efficacy and appropriateness of various operational strategies. This paper aims to take stock of these assumptions and examine the extent to which the design and implementation of community-based distribution (CBD) programs in Africa have been guided by evidence.

\section{WHAT IS CBD?}

Family planning programs often augment clinical services with social marketing, satellite clinics, ${ }^{1}$ employer-based programs, private-sector programs, and other forms of family planning outreach such as home visitation by trained distribution agents. "Community-based distribution" (CBD) refers to programs of nonclinical family planning service approaches that use community organization, structure, and institutions to promote the use of safe and simple contraceptive technologies. ${ }^{2}$

In Africa, community-based family planning programs typically focus on the provision of oral contraceptives, foam tablets, and condoms. ${ }^{3}$ In order to promote methods that provide dual protection (from pregnancy and from sexually transmitted diseases [STDs]) as a conscious choice, a CBD program's activities may include prevention strategies for AIDS and other STDs. ${ }^{4}$ Similarly, CBD may be conducted as a component of community health outreach. In some CBD projects, local volunteers operate health posts in village locations, ${ }^{5}$ or volunteers may operate depots where family planning supplies and information are available. ${ }^{6}$ In some programs, CBD employs salaried nonparamedical workers who 
visit households and provide condom and pill services. ${ }^{7}$ CBD may also involve household visits from volunteers for contraceptive education or distribution or clinical referrals. ${ }^{8}$ Alternatively, market traders may sell contraceptives alongside their other wares in traditional markets. ${ }^{9} \mathrm{CBD}$ contrasts with social marketing, which typically involves pharmacies rather than traditional market vendors, but $\mathrm{CBD}$ can be designed to have close operational links with social marketing efforts. ${ }^{10}$

CBD is thus a complex concept, involving varied operational designs. Nonetheless, a common underlying assumption guides all CBD initiatives: Offering family planning services at nonclinical community locations expands the acceptability and convenience of contraceptives and reduces the costs of contraception, thereby extending use among clientele who seek contraceptives but will not use services that are confined to clinical settings (see Ross et al. 1987 and Ross and Frankenberg 1993).

The theme of extending accessibility is neither new nor unique to the family planning field. ${ }^{11}$ Agricultural innovations, for example, have been disseminated by extension agents (see Wolf 1986). In postcolonial Africa, the practice of training locally selected agents to educate subsistence farmers has led to more rapid diffusion of agricultural innovations than has occurred in the absence of community outreach (see Leonard 1977). This experience, together with the experiences of environmental, health, and community development programs, has led social researchers to advocate community-based strategies for fostering behavioral change in traditional societies. By basing programs within the communities they serve, communication and societal barriers to the spread of innovation are diminished. ${ }^{12}$

\section{CBD Assumptions}

As CBD programs have been developed throughout Africa, various assumptions have guided their operational design and presumed consequences. The 
conventional view is of $\mathrm{CBD}$ as a single strategy that addresses the problem of family planning inaccessibility under the assumption that a lack of convenient access to contraceptives represents the primary barrier to the practice of family planning. According to this view, inaccessibility constrains method adoption and use, rather than societal barriers such as a woman's belief that her husband disapproves of contraception.

Some nonclinical strategies are not generally included in conventional definitions of CBD. Family planning outreach that is not community based, such as employer programs, is not considered CBD unless entire communities of workers' families are targeted with household visitation. Promotional social marketing programs are not defined as $\mathrm{CBD}$, although organizers of traditional marketvendor schemes characterize their programs as $\mathrm{CBD}$, because delivery points use community-based markets.

Assumptions about the efficacy of CBD in Africa derive largely from the legacies of CBD in other regions (Freedman 1987). Community-based distribution programs originated in Asia in the 1960s with projects in Indonesia, Korea, Taiwan, and Thailand that led to a proliferation of the strategy throughout Asia and Latin America in the 1970s and 1980s. ${ }^{13}$ Early research demonstrated that CBD was feasible, effective, safe, and important to success at the national level in several Asian and Latin American countries, suggesting that contraception was in demand and that nonclinical community distribution was feasible and acceptable to local populations. ${ }^{14}$ In several important instances, this conclusion was based on pilot projects and experiments showing that CBD was a viable servicedelivery option for national family planning programs.

\section{CBD EFFORT in SUb-SAHARAN AFrica}

CBD programs have expanded in sub-Saharan Africa over the past two decades. A review of 93 developing countries in 1984 concluded that CBD was functioning in 34 countries around the world, seven programs of which were 
operating in sub-Saharan Africa (see Ross et al. 1987). As Figure 1 shows, the strength of CBD effort has expanded considerably during the 1980s and 1990s, as programs have grown to serve greater proportions of the population. Countries with CBD coverage of less than 21 percent are considered to have "weak" effort, whereas those in which CBD programs cover 21 percent or more of all areas are considered "strong" (see Ross et al. 1987). Where CBD was weak in the 1980s, programs were constrained by medical conservatism, policy inertia, bureaucratic inertia, and operational uncertainty in Africa. Because most sub-Saharan African countries registered little or no progress in launching CBD programs or effort, most of the population of the region was unexposed to outreach services. By 1989, however, this situation had changed dramatically. Although programs in Sierra Leone and Mauritius regressed from having strong CBD programs in 1982 to having no CBD effort in 1989, six countries (Ghana, Kenya, Lesotho, Nigeria, Tanzania, and Zambia) strengthened CBD policies from having no CBD effort in 1982 to having weak or strong effort by $1989 .{ }^{15}$ By 1996 , CBD programs had begun in six additional countries (Benin, Central African Republic, Malawi, Mali, Sudan, and Uganda). Although coverage within countries is variable, and actual rates of exposure to CBD activities are unknown, almost half of the population of sub-Saharan Africa lived in countries exhibiting some CBD effort by 1996. This proliferation of CBD has been fostered by policies of the United States Agency for International Development (USAID), the United Nations Population Fund (UNFPA), and German Technical Cooperation (GTZ), all of which have made CBD a routine part of external assistance to family planning programs. Although only three countries had strong CBD efforts in 1996, most observers agree that outreach services reached a majority of the villages in each "strong" CBD country. ${ }^{16}$

Figure 2 presents a map of Africa illustrating recent CBD activities of government and nongovernment agency programs, research initiatives, and pilot pro- 
Figure 1 Sub-Saharan African countries, by level of CBD effort, ${ }^{a} 1982-96$
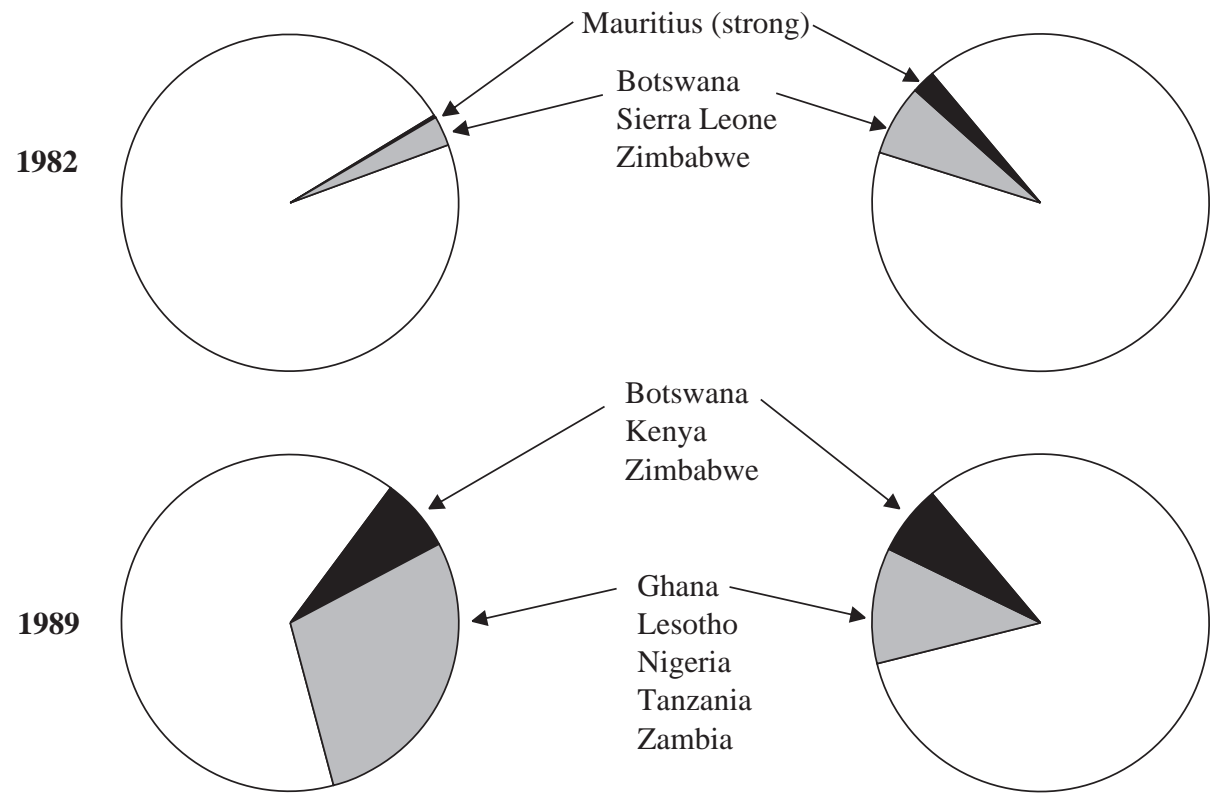

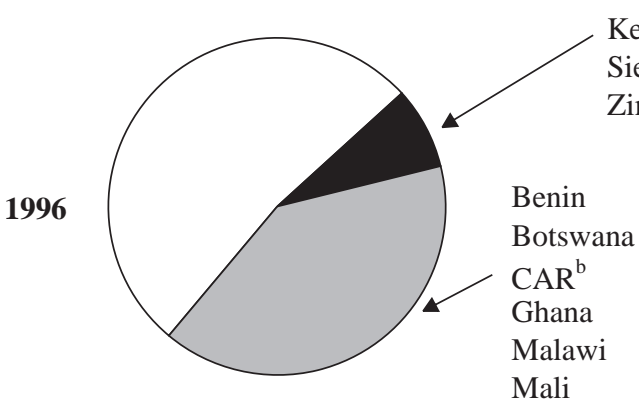

Weighted by mid-year population

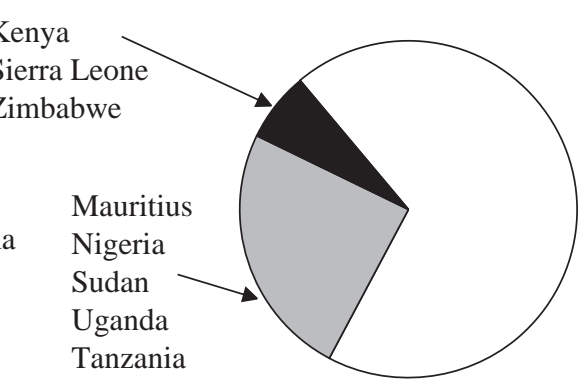

Weighted by country

$\square \quad$ No CBD effort
$\square \quad$ Weak
$\square$ Moderate/strong

\begin{tabular}{ll}
\multicolumn{2}{l}{ No CBD any year } \\
Angola & Djibouti \\
Burkina Faso & Equatorial-Guinea \\
Burundi & Eritrea \\
Cameroon & Ethiopia \\
Chad & Gabon \\
Congo & Gambia \\
Côte d'Ivoire & Guinea-Bissau
\end{tabular}

Liberia
Madagascar
Mauritania
Mozambique
Namibia
Niger
Réunion

Rwanda

Senegal

Somalia

South Africa

Swaziland

Togo

Zaire/DRC ${ }^{\mathrm{c}}$

${ }^{a}$ Countries are categorized using the CBD scale employed by Ross et al. (1987). Scores range from 0-4 and are based on responses to questions on the program's efficiency, whether the program provides both initial and supply/resupply of contraceptives, whether it serves both rural and urban areas, and the proportion of the population that is covered within each area. $\quad{ }^{\mathrm{b}} \mathrm{CAR}=$ Central African Republic. $\quad{ }^{\mathrm{c}} \mathrm{DRC}=$ Democratic Republic of the Congo. 
Figure 2 Sub-Saharan countries with CBD programs, pilot projects, or research activities, 1994-98

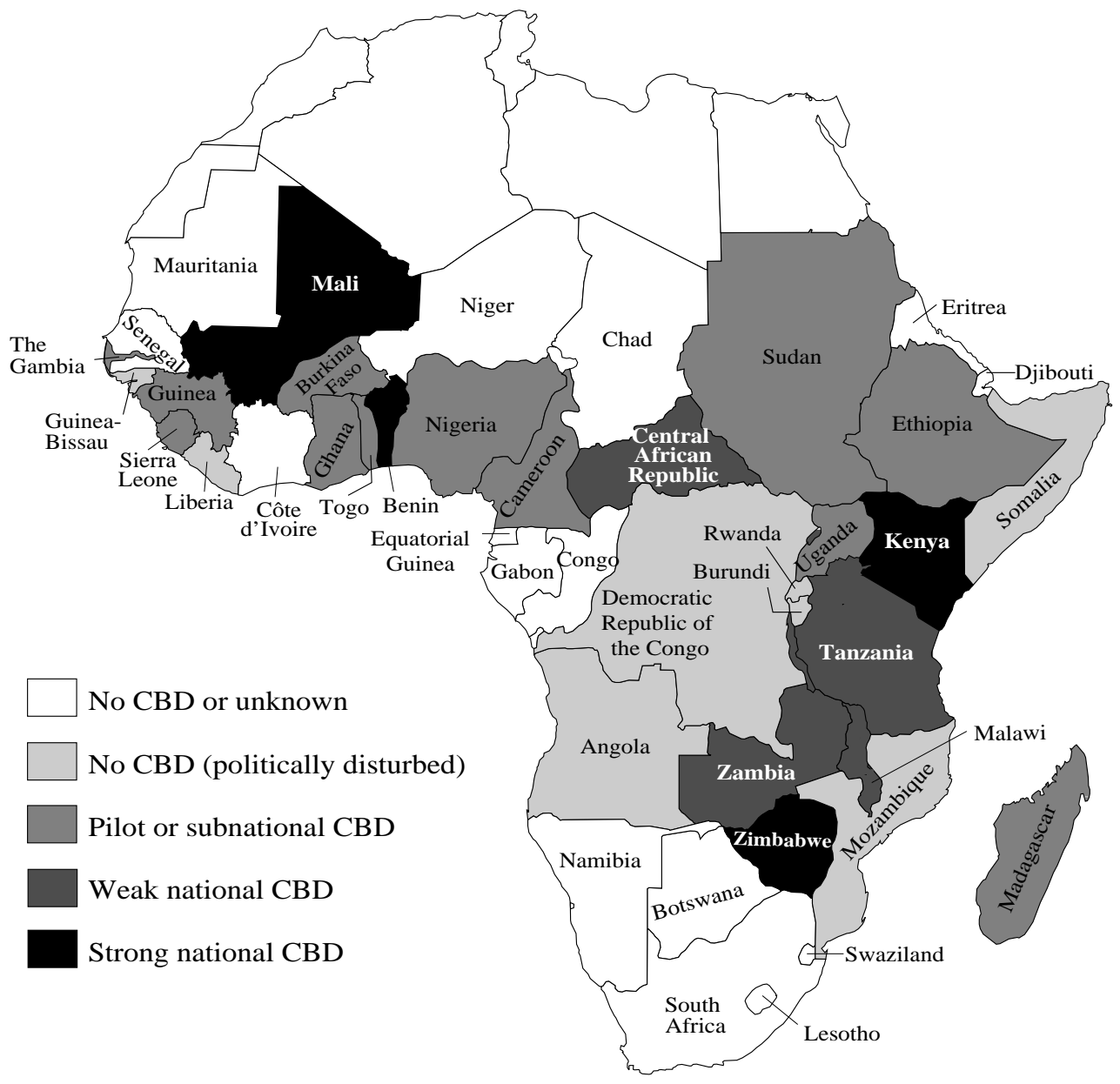

grams. In all, 20 countries in Africa had at least one initiative in the five years from 1994 to 1998 . Four countries have strong national CBD programs. In Kenya alone, 25 separate initiatives are providing community-based services through a variety of institutional arrangements. ${ }^{17}$ In Zimbabwe, a national CBD program is constituted through a single parastatal agency. Thus, although CBD can be said 
to be a relatively recent development in the sub-Saharan region, considerable $\mathrm{CBD}$ experience has been accumulated there, and effort has been greatly expanded in the region during the 1990s. Table 1 lists CBD efforts in Africa by country from 1994 to 1998.

\section{CBD Impact in Sub-Saharan Africa}

Because of the Asian and Latin American legacies, CBD is viewed as the single most important family planning innovation (see Huber et al. 1975, Foreit et al. 1978, Kols and Wawer 1982, and Gallen and Rinehart 1986). However, apart from evidence that CBD increases contraceptive use in settings where unmet need is high, evidence that CBD is "successful" is limited. Only one study has demonstrated that $\mathrm{CBD}$ reduces fertility. No study has shown that CBD avoids negative social consequences or enhances the status of women in sub-Saharan Africa. Although CBD is justified as a means of meeting unmet need by making contraceptives available to women, one study has shown that CBD actually increases unmet need (see Debpuur et al. 1998). Although the assumption is generally made that geographic inaccessibility constrains contraceptive use, research has shown that social constraints play a greater role in determining unmet need than does geography (see Nag 1984, Bongaarts and Bruce 1995, and Rutenberg and Watkins 1996). Perhaps the greatest strength of CBD is its potential to involve communities and foster male approval of family planning, thereby having an impact on spousal communication and unmet need, but this role has yet to be clarified. One experimental study in Mali demonstrated that CBD increased spousal communication more than other family planning program components were able to (see Katz et al. 1998). Thus, the impact of CBD on contraceptive use has been established, but the more general causal basis for this impact is poorly understood.

The success of a CBD program typically is measured by assessing the extent to which $\mathrm{CBD}$ strategies increase contraceptive use, over and above levels 


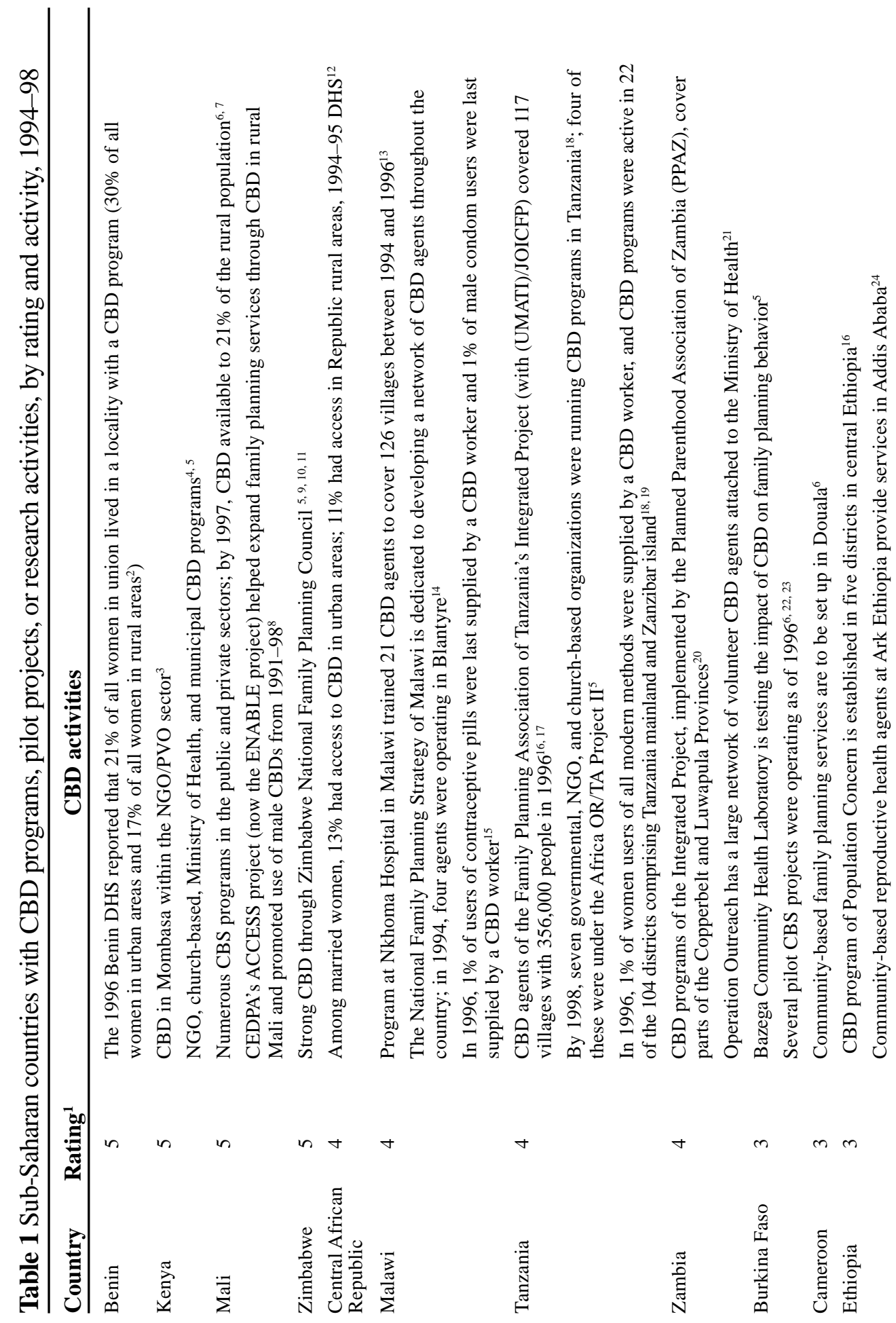




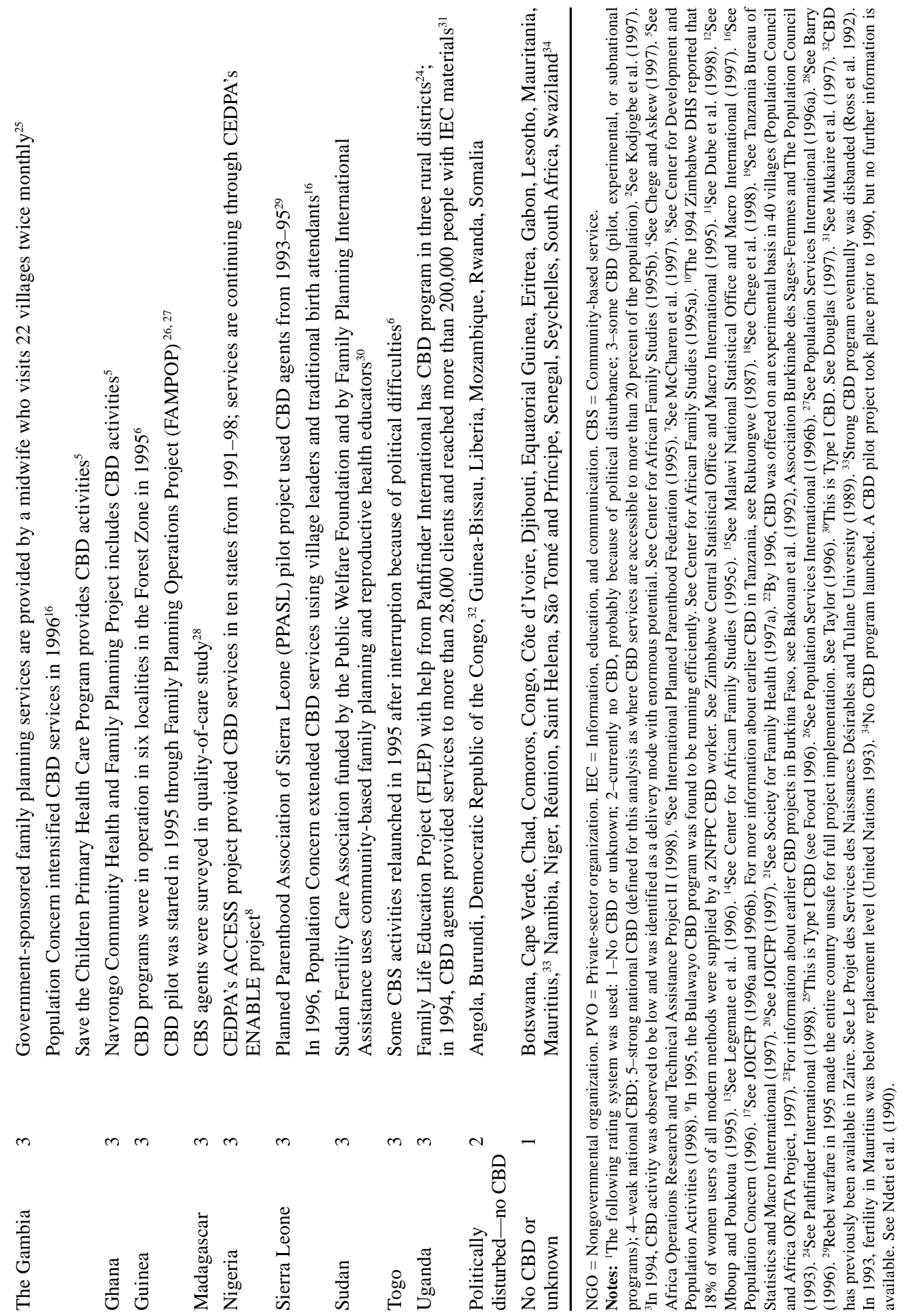


that would be expected in the absence of such a program. According to this basic criterion, evidence is accumulating that $\mathrm{CBD}$ can be successful in Africa. Seven experimental studies have been launched, only one of which demonstrated null effect on contraceptive use (see Table 2). A recent study conducted in Mali demonstrated that $\mathrm{CBD}$ had an impact on contraceptive knowledge and contraceptive use (see Katz et al. 1998). (An earlier Mali study demonstrated an increase in contraceptive prevalence from 1 percent to 31 percent over a two-year intervention period. Although no control group was used, the authors argued that their study demonstrated the effectiveness of a rural CBD program in the Mali setting [see Doucoure et al. 1996]).

In the Gambia, CBD through traditional social institutions increased contraceptive prevalence by 10 percent among women most likely to practice contraception (see Luck et al. 1996). In Kenya, the use of traditional health practitioners as CBD agents increased contraceptive prevalence by more than 17 percent (see AMREF and the Population Council 1993). Two experiments in Ghana have demonstrated an impact on contraceptive use. One of these projects, in Danfa, used a mobile family planning clinic and comprehensive health-care approach to demonstrate that ever use of modern contraceptive methods increased by 23 percent in the experimental area receiving the most comprehensive health care over the project period. CBD services reportedly tripled contraceptive acceptance rates, although the Danfa experimental design does not allow for specific analysis of the effect of CBD on contraceptive prevalence (see University of Ghana Medical School 1979 and Kwansa 1990).

The second Ghanaian experiment, in Navrongo, showed that CBD increased contraceptive use in treatment areas relative to comparison areas. This change in reproductive behavior reduced the TFR by 0.4 births in the first year of project observation (see Debpuur et al. 1998). An ongoing Burkina Faso experiment has produced preliminary evidence that $\mathrm{CBD}$ doubled contraceptive prevalence from 
4 percent to 8 percent in a rural district, and further effects may be found as this study continues. ${ }^{18}$

All but one of these successful CBD experiments took place in West Africa, in areas with extremely low contraceptive prevalence. The impact of CBD may be greatest in such areas. A CBD approach may be particularly good for introducing a new service because of its suitability for diffusion. ${ }^{19}$

Experimental studies demonstrating CBD effects have been conducted in settings of low contraceptive prevalence. Statistics from Kenya and Zimbabwe suggest that rigorous national CBD efforts have provided substantial proportions of the contraceptive supplies and services that are furnished to couples in those countries. ${ }^{20}$ The timing of the CBD effort in Kenya was associated with subsequent increases in method use (see Hammerslough 1992). Whether CBD is necessary to sustain demographic change in Kenya is unknown, however, and is widely debated. Once contraceptive prevalence increases, CBD may not be as important to family planning programs as it is in settings where prevalence is low. Family planning initiatives in Kenya have sometimes succeeded with fixed clinical service strategies that are not characterized by CBD approaches (see Goldberg et al. 1987). Moreover, situation analysis in Zimbabwe has shown that health depots can function effectively as CBD in resupplying women with contraceptives (see Dube et al. 1998). Thus, the general impression conveyed by Table 2 is that CBD has an impact on contraceptive use, although this impact is sometimes weak, inconsistent, and difficult to separate from the effects of other family planning program components. Clarifying the demographic roles of CBD and clinical family planning services would require controlled experimental studies in a variety of cultural, demographic, and institutional settings.

Furthermore, the fertility effects of CBD are typically unknown, because scientifically rigorous appraisals of CBD fertility impact are lacking. Evaluation studies of CBD impact have focused on contraceptive use. Anthropological stud- 


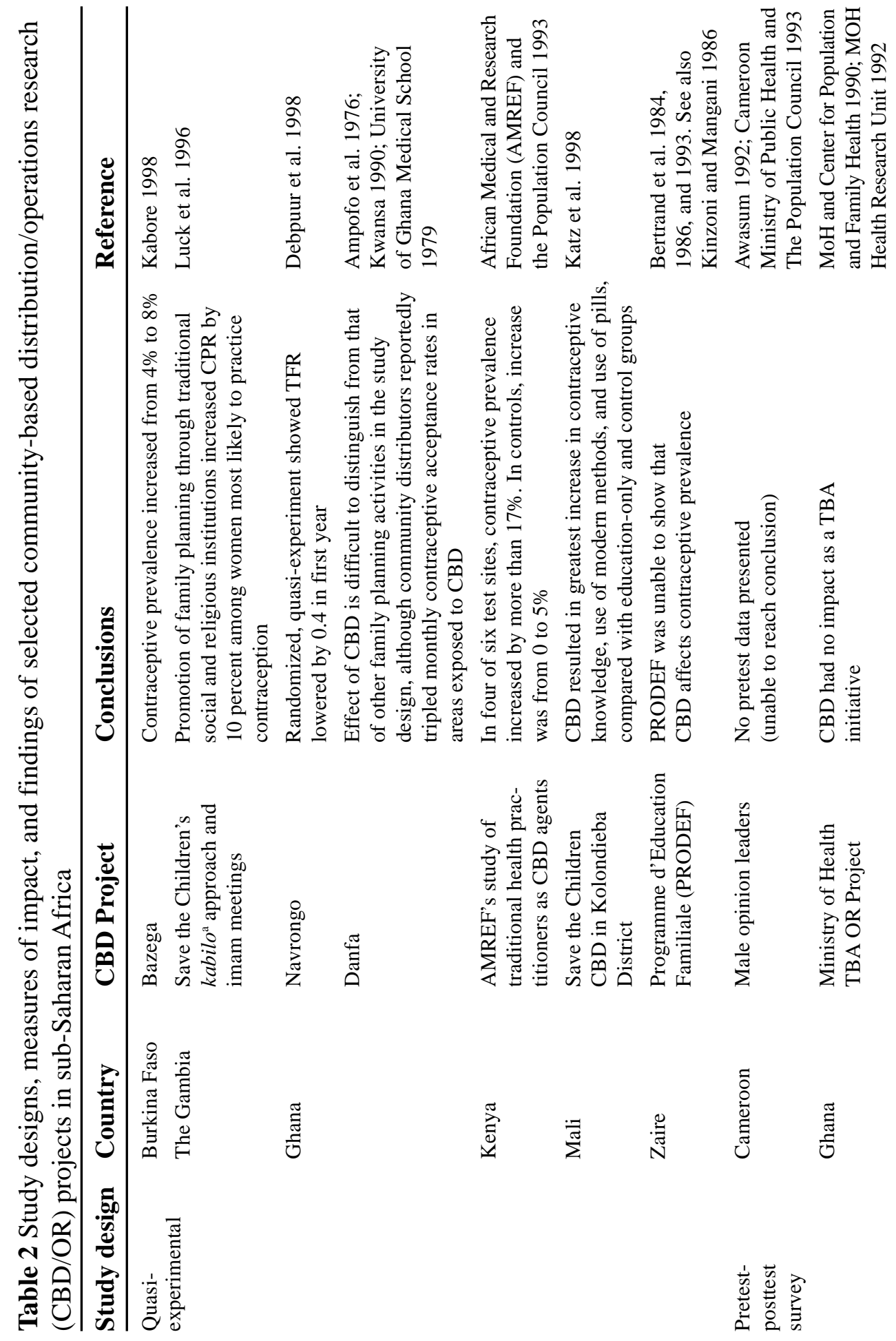




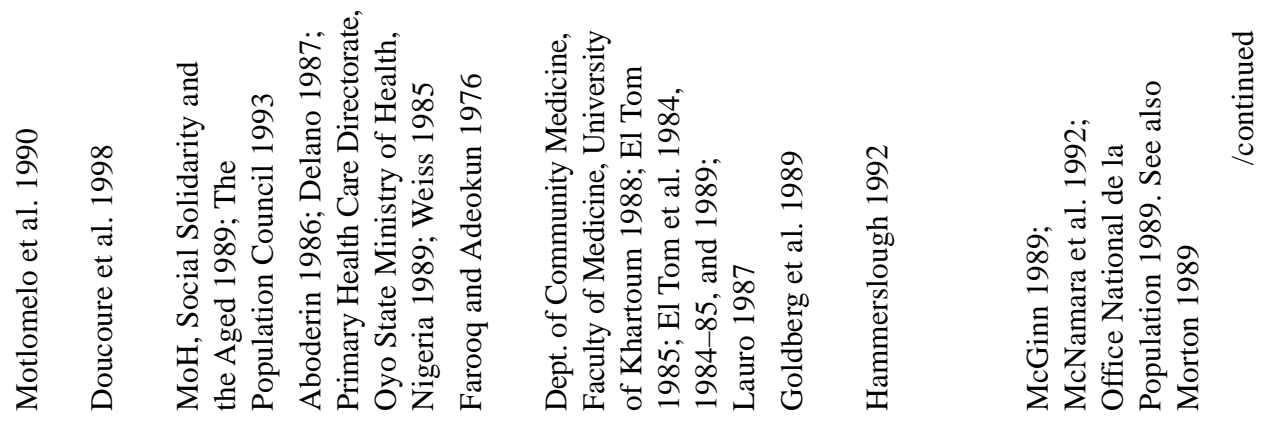

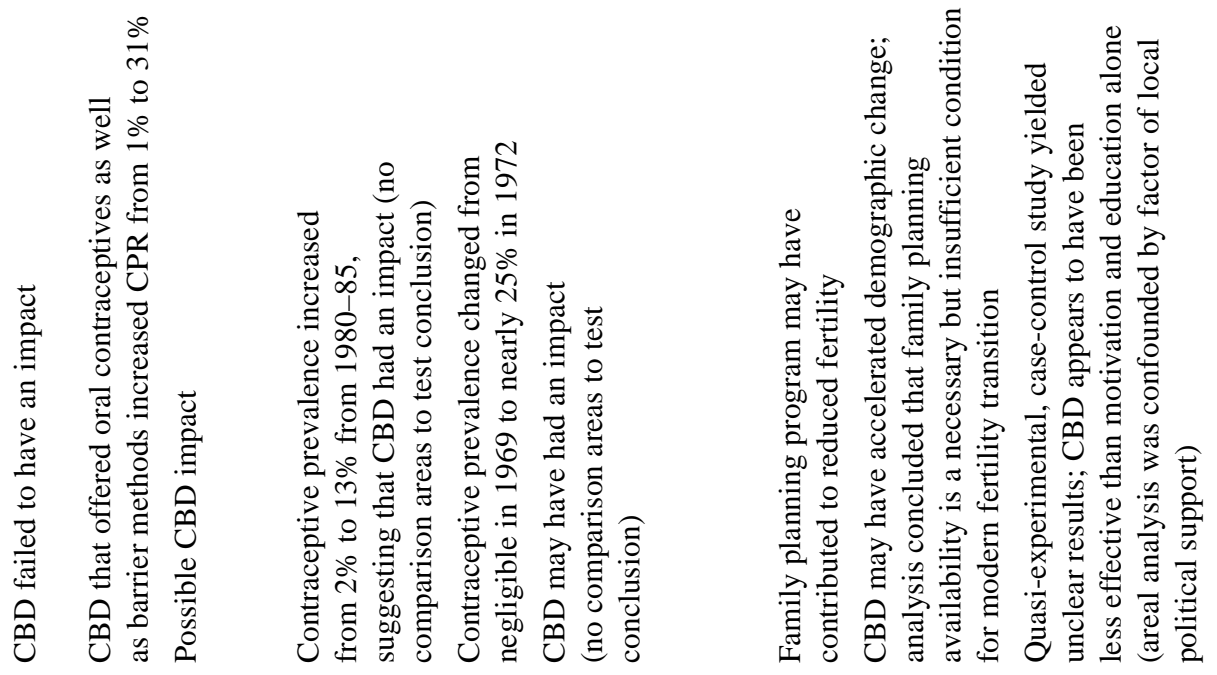

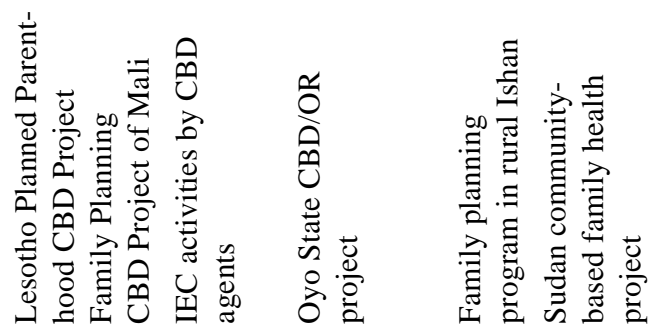

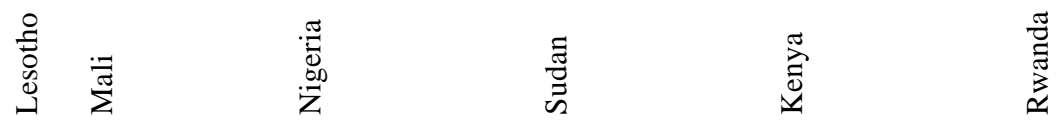

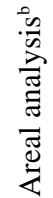




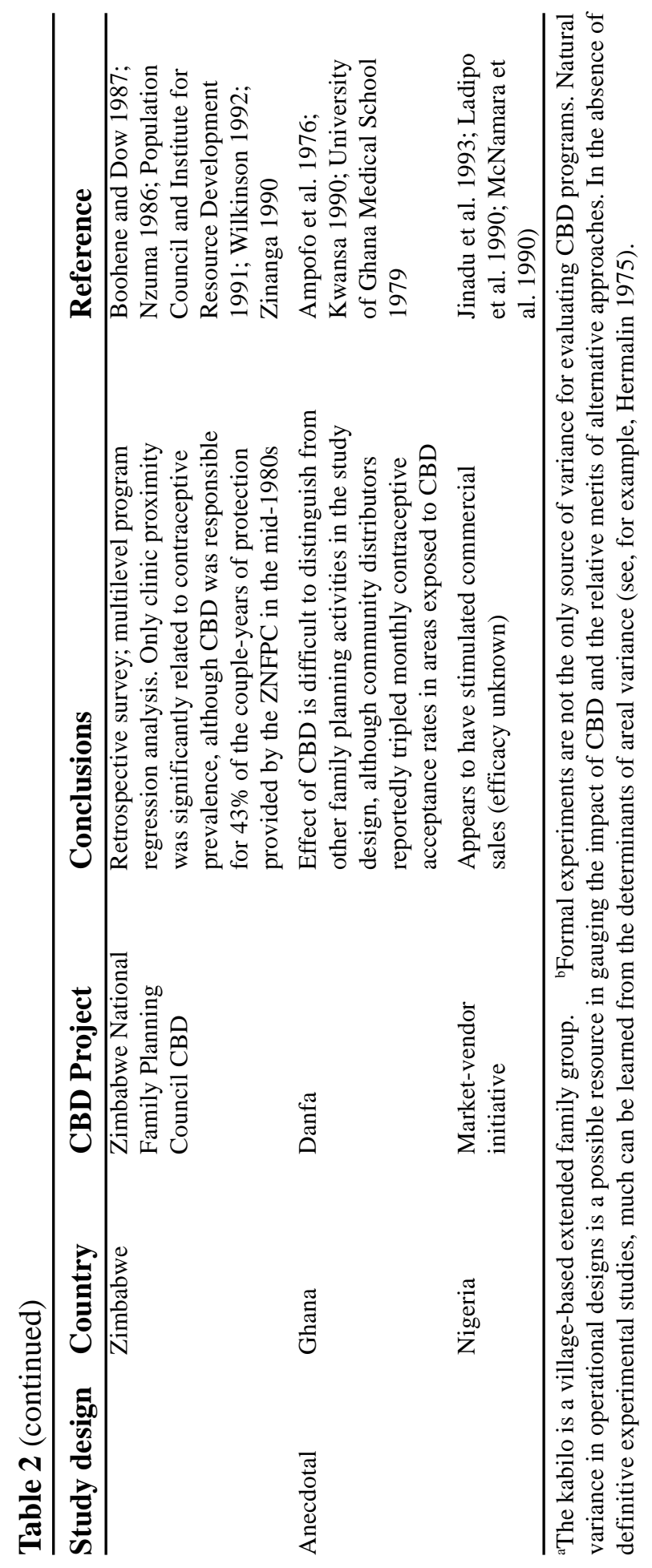


ies of birth-interval dynamics and reproductive behavior in Africa, however, show that postpartum abstinence is prolonged and that contraceptive adoption often substitutes for abstinence. Thus, contraception may have little or no fertility impact within this dynamic (Bledsoe et al. 1994). Although ultimately research may demonstrate that $\mathrm{CBD}$ affects fertility, African demographic transitions are likely to be different from such transitions in other parts of the world where contraceptives are primarily used to limit births. ${ }^{21}$ They will probably be more gradual and affect women of all ages rather than only those older women who have reached their desired parity. The role of CBD in this unique region is unknown.

\section{TYPES OF CBD}

The typology in Figure 3 illustrates assumptions about CBD that characterize the intersection of demand for contraception and its supply. Information and service provision can be intensified through convenient nonclinical outreach,

Figure 3 A typology for CBD models in sub-Saharan Africa

The client is assumed to be...

\begin{tabular}{|c|c|c|}
\hline & $\begin{array}{c}\text { Passive } \\
\text { (non-service seeking) }\end{array}$ & $\begin{array}{c}\text { Active } \\
\text { (service seeking) }\end{array}$ \\
\hline $\begin{array}{c}\text { assumed to be... } \\
\text { Passive } \\
\text { (delivery-point-based) }\end{array}$ & $\begin{array}{c}\text { No CBD } \\
\text { (Passive-Passive) }\end{array}$ & $\begin{array}{l}\text { Type I } \\
\text { •Depots } \\
\text { •Market approaches }\end{array}$ \\
\hline $\begin{array}{c}\text { Active } \\
\text { (client seeking) }\end{array}$ & $\begin{array}{l}\text { Type II } \\
\text { (also called CBS) } \\
\text { Doorstop services } \\
\text { provided by } \\
\text { •Paid workers } \\
\text { • Volunteers }\end{array}$ & $\begin{array}{l}\text { Type III } \\
\text { •Community } \\
\text { mobilization } \\
\text { schemes } \\
\cdot \text { Complex CBD }\end{array}$ \\
\hline
\end{tabular}


as shown by the arrow at the side of the diagram. The client dimension defines assumptions about the role of clientele in CBD. "Active" clients must be motivated to use contraceptives, even if they must travel for services or bear other costs. The program dimension alternatively defines programs as "passive" (offering services at fixed points such as village depots or markets) or "active" (providing outreach to homes).

The typology implies three contrasting models for the intersection of supply of services and demand for care. A totally clinical program for passive clients defines an interface between supply and demand that will not work (the passivepassive condition). The passive-passive situation in Africa explains why CBD is needed as a policy option. Type I CBD programs emphasize fostering demand through information, education, and communication, and through other strategies that motivate clients to adopt services at convenient fixed delivery points such as village health posts, satellite clinics, kiosks, and traditional markets. ${ }^{22}$ This approach is based on the assumption that the costs of contraceptive supply at fixed facilities are not unacceptably high. ${ }^{23}$ Alternatively, CBD can be offered as a doorstep service (Type II), with the assumption that demand for services is insufficient to motivate people to use fixed facilities. ${ }^{24}$ Doorstep services involve household visitation by voluntary or paid CBD agents. Where demand for family planning is fragile and new, comprehensive programs are required that involve combinations of Type I and Type II approaches. This condition is illustrated in the lower right quadrant of Figure 3. Not only are services offered at fixed service points in convenient village locations, but doorstep and other outreach activities are also pursued. With this approach, programs not only provide convenient access to supplies but they also attempt to foster changes in beliefs and behaviors and to encourage social change by combining elements of Type I and II programs with strategies for achieving comprehensive community involvement. Comprehensive Type III CBD that effectively develops demand in the con- 
text of offering convenient contraceptive supplies may be crucial to the success of family planning in the sub-Saharan region.

Each type has a unique set of organizational requirements. Type I is described in the first column of Table 3, whereby CBD agents use a passive village supply depot. Type I is usually developed by a large-scale integrated service agency that adds CBD health posts to an existing clinical program. In this model, the CBD service regimen is focused appropriately on both health and family planning, because people will travel to a depot or to satellite clinics for health care even if they do not seek family planning services. Thus, in the Type I system, contraceptive services are often organized around what is in demand, such as health care, or around some other sought-after service (such as convenient marketing) rather than around family planning per se. ${ }^{25}$

The success of the Type II organizational strategy is derived from training agents to become efficient, effective, and active doorstep outreach workers. The community is consulted about choice of agent, and liaison with the community is given considerable attention. In successful Type II CBD programs, communities are typically not involved in financing, supervision, or other routine management functions. Type II CBD is also called CBS, community-based service, because it involves the community in agent selection (International Planned Parenthood Federation 1995).

Both Type I and Type II approaches require formal administrative systems, with professional staff, paid CBD agents, and certificate training. In doorstep $\mathrm{CBD}$, agents are assigned to specific geographic areas, are given a target number of households to cover, and are supervised individually. Employer-based programs that provide the families of workers with contraceptive services in their homes are also considered Type II CBD. ${ }^{26}$ In general, the principal administrative unit is the clinic, and all logistics, management information systems, and other forms of institutional backup are oriented to clinical services with CBD as outreach. 


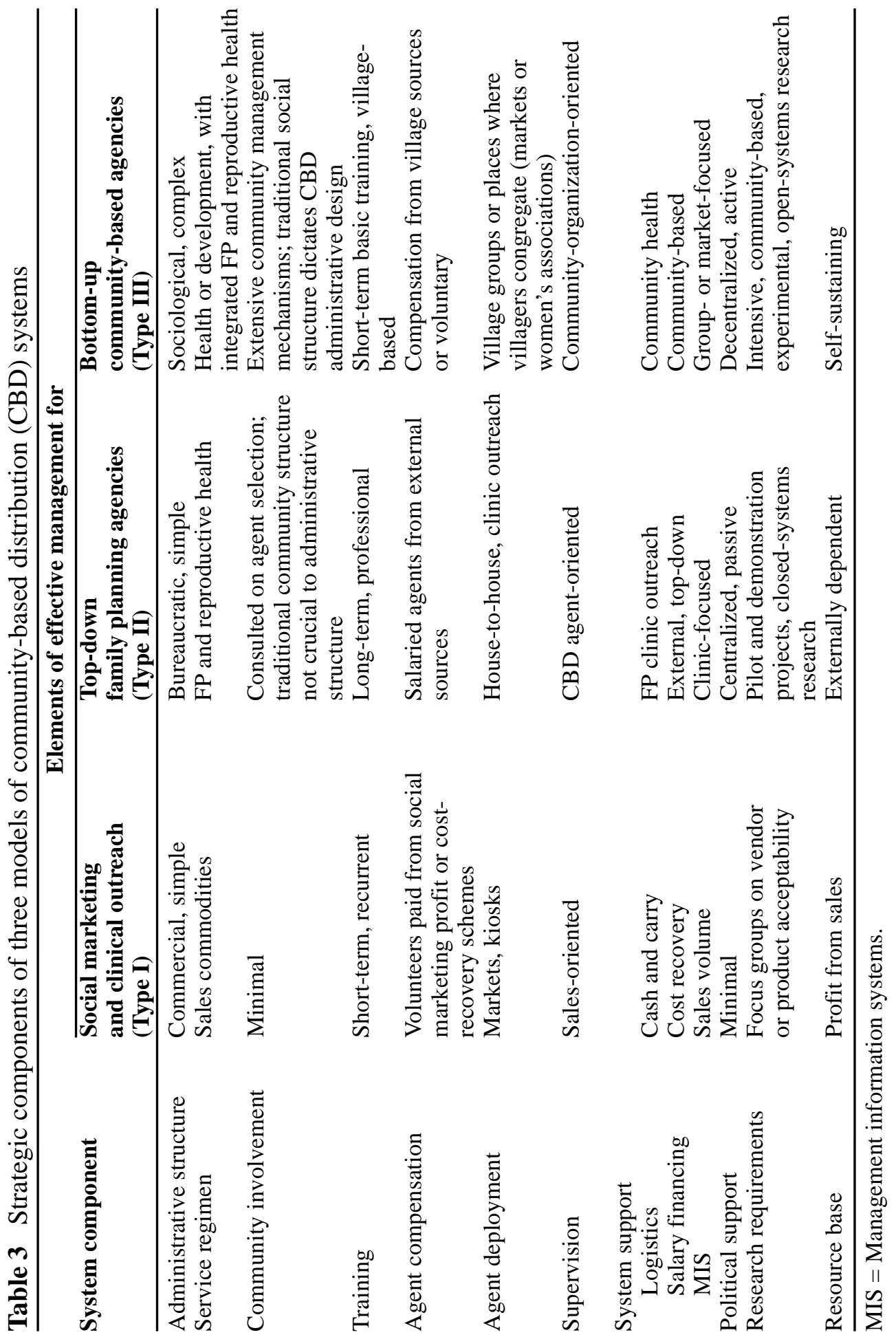


Although expensive and often dependent upon external resources, Types I and II are the simplest CBD options, involving the fewest questions requiring research. Research can be focused on "closed systems" questions about streamlining operations, building managerial capacity through pilot testing, and situation analyses to monitor progress and diagnose administrative problems. Type I and II approaches are amenable to transfer from country to country: The Zimbabwe model is considered workable in other countries if donors were committed to the scale of external support that such an effort entails. CBD organized on Type I or II models benefits from political support, but is not dependent upon it for success.

A Type III CBD approach is more challenging to organize than are the Type I and Type II approaches, because this strategy involves mobilizing entire communities for service delivery rather than motivating paid employees of a bureaucracy. As the table shows, effective Type III programs are often decentralized or are administered by agencies with centralized management that rely heavily on traditional leaders for guidance. This approach results in decentralized, locally adapted programs that are integrated into local social institutions. Type III CBD programs also rely heavily on volunteers and provide a broad range of community health or social services. In some instances, Type III programs are closely linked to women's movements or to national political parties.

The assumptions underlying the operational designs of CBD in Africa can thus be diverse. Although CBD is often discussed as a single strategy for extending services to convenient locations, it is more appropriately viewed as many different strategies, each with specific organizational requirements.

\section{HOW CBD WORKS IN AFRICA}

For three decades, discussions about the demographic role of family planning have focused on the relative role of the supply of services and the demand for family planning. ${ }^{27}$ Extreme positions in this debate have been discredited in recent years, and a consensus is emerging that the supply-demand dichotomy 
represents an unrealistic and overly mechanistic view of human reproductive behavior (see Simmons 1992). Social, economic, and cultural conditions play a crucial role in defining reproductive norms and family planning behavior; family planning programs interact with these sets of influences to introduce and sustain reproductive change. $\mathrm{CBD}$ is often seen as the best way for family planning programs to achieve their goals.

Three possible roles for the impact of CBD on reproductive behavior are implied by the social research literature, as synthesized by the framework adapted from Easterlin (1975a and 1975b) and illustrated in Figure 4. In this framework, social-structure factors and characteristics of individual couples determine fertility-control motives, ${ }^{28}$ which affect the pace of childbearing, with the demand for children functioning as a key intermediate factor. Motivation to practice fertility regulation is a function of fertility motives ( $a$ in Figure 4 ) and fertility regulation costs $(b)$. Family planning programs influence fertility by mitigating costs $(c){ }^{29}$ Programs may also influence fertility-control motives and the demand for children through information, education, and promotional campaigns $(d) \cdot{ }^{30}$ Of the possible pathways for effects that are illustrated in the figure, CBD is conventionally viewed as a cost-mitigating strategy rather than a demand-generating strategy. As such, CBD programs are justified as initiatives to fulfill unmet need for contraception. However, some research suggests that where contraceptive prevalence is very low, the promotion of family planning can have an impact on knowledge of methods and preferences to use them and that CBD programs can thereby generate demand for family planning that would not otherwise arise $(d$ and $e$ ). ${ }^{31}$ This "beyond supply" effect of CBD is suggested by the observation that changing demand for children often follows, rather than precedes, the introduction of family planning programs. ${ }^{32}$ Whereas this latent demand for family planning was extensive in Asia and Latin America, in Africa the demand for children is extensive and contraceptive demand is relatively weak. ${ }^{33}$ The demand- 
Figure 4 Basic models of factors determining fertility

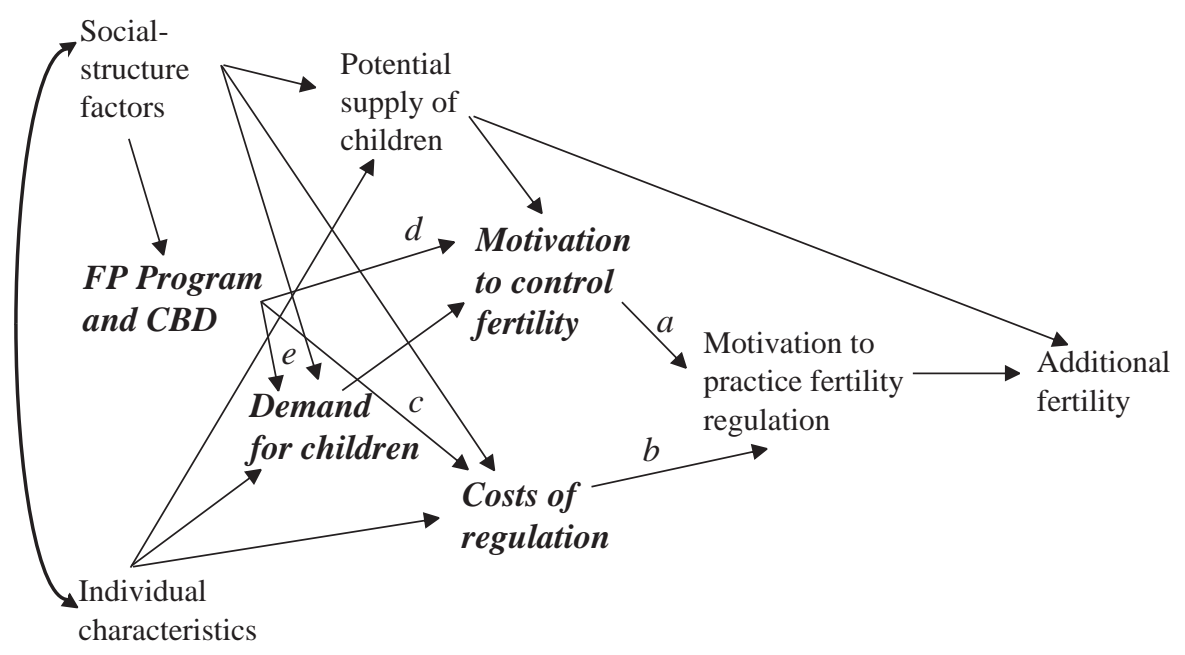

Source: Adapted from Hermalin 1983.

generating function of $\mathrm{CBD}$ may have a greater role in shaping the demographic impact of services in Africa than has been the case in other regions. ${ }^{34}$

The role of CBD in mitigating the costs of family planning is specified by pathway $b$ in the figure. CBD can help couples with unmet need for family planning by mitigating monetary costs of contraception in several ways: by placing services in convenient locations; by offsetting social costs of fertility regulation through offering information and services in a manner that dissipates familial barriers or other opposition to family planning; by averting psychological costs of contraception through counseling or correcting misinformation; and by reducing health costs of side effects with treatment or follow-up services.$^{35} \mathrm{CBD}$ programs are typically focused on enhancing women's access to family planning. Survey data suggest, however, that geographical access is a less important determinant of contraceptive use than are lack of knowledge, fear of side effects, and social or familial disapproval (Nag 1984; Bongaarts and Bruce 1995; Rutenberg 
and Watkins 1996). ${ }^{36}$ Systematic understanding of these cost constraints is needed in a $\mathrm{CBD}$ operation so that workers can be trained to address the key costs of contraceptive use. In the African context, these costs are related to the absence of spousal, familial, or social support for contraception. ${ }^{37}$ Bringing social structure into account in the operational design of $\mathrm{CBD}$ will be more important in Africa than has been the case in other regions.

The Easterlin determinants of contraceptive use have implications for policy priorities in the design of CBD programs. Type I programs assume that the demand side (pathways affecting $a$ in Figure 4) is sufficiently strong and the costs of contraception (pathways affecting $b$ ) are sufficiently low for people to seek services away from their own doorsteps. Type II programs, on the other hand, tend to focus on the mitigation of accessibility costs by bringing services to women in their own homes. In practice, there may not be a sizable difference between the client costs of Types I and II, because Type I programs generally require a woman to travel only to a depot in her village or to a market that she probably visits routinely. Type III CBD is unique, however, because of its focus on mitigating social costs through the intense involvement of traditional institutions. As an approach that is designed to mitigate social costs as well as to address the need for convenience, Type III CBD is likely to be the most appropriate strategy for Africa, particularly in areas with low demand and prevalent constraints to family planning adoption.

\section{The Implications of Social Costs for CBD Design}

Addressing social costs is not only crucial to the efficacy of CBD, it is critical for designing programs that do not have an adverse impact on the lives of the women they serve. ${ }^{38}$ The overemphasis on accessibility may have distracted attention from these detrimental social costs. Possible areas of social cost have been noted in the literature:

First, programs targeted to the needs of women in Africa may inadvertently isolate them from family members (Adepoju and Mbugua 1996). This over- 
emphasis on outreach to individual women may interfere with reproductive decisions typically made by men or by couples in which women are traditionally the least powerful participants in decisionmaking.

This marginal role of women in reproductive decisionmaking derives from the custom of bridewealth, which inculcates the prevalent belief that women are property purchased by the corporate family for the purpose of producing heirs for the lineage. A woman approached by an outsider who offers her a family planning method and services may be embarrassed at best. A man aware of this encounter may feel threatened as a man and as a property owner and embarrassed as a member of his social group. Doorstep CBD approaches can thus precipitate social discord that has a selective and negative impact on women. Although contraception can give women greater control over reproduction and autonomy in other areas of their lives, these effects can be offset in a context with limited opportunities for education or gainful employment for women outside the home (see Simmons and Young 1996).

Second, reproductive autonomy fostered by contraception may threaten men who derive status from their reproductive dominance, thereby producing adverse social consequences for women who adopt family planning. ${ }^{39} \mathrm{CBD}$ effort in gender-stratified settings requires a component of male outreach to mitigate the social discord that can arise from increased contraceptive use. ${ }^{40}$ The more active the CBD program is, the greater the attention that should be paid to allaying men's concerns. Outreach strategies must be tailored to each community, because sociocultural constraints to family planning vary throughout Africa. For instance, men in West Africa are more likely to disapprove of family planning and to want more children than are men in East Africa (Drennan 1998).

Spousal communication is often a key to accurate perceptions about reproductive preferences, and couples who discuss family planning are more likely to practice contraception (see Drennan 1998). Protecting the privacy of women may be more important, however, than encouraging spousal communication in situa- 
tions where women's contraceptive use can have harsh consequences if it is discovered by their husbands (see Biddlecom and Fapohunda 1998).

Third, marriage is symbolic of a fertility contract between extended families, to whom childbearing is a source of status and prestige. In this tradition, a woman found to be practicing contraception has violated the marriage agreement between families. She may be sent home to her father in disgrace, and ostracized by her kin. Divorce, discord, or violence may ensue. On the other hand, women who bear children gain status. Research has shown that as Yoruba women have more children, their power in reproductive decisionmaking increases and their social autonomy improves (Bankole 1995).

A well-designed CBD approach may avoid social discord, however. Community-based health and social programs in Africa can benefit from the strong traditions of social organization that define patterns of opinion leadership, organize collective responses to external initiatives, and structure community relations. One successful program in the Gambia used kabilos, village-based extended family groupings, and imam meetings, with religious leaders, to recruit CBD agents and gain support for family planning. Contraceptive prevalence was increased by 10 percent (see Luck et al. 1996). If CBD is designed to mitigate the social costs of contraception, social discord may also decrease. Approaches that seek to defray these costs through community involvement and support will be in a position to monitor and address conflicts that arise. If such approaches are not used, CBD may well increase the social costs of family planning for women, men, and extended families.

\section{The Implications of Constrained Demand for Contraception}

Africa is often characterized as a region with social, economic, and cultural institutions that influence reproductive motives profoundly and constrain the onset of demographic transition. ${ }^{41}$ High-fertility motives are grounded in complex social institutions (see National Research Council 1993). For example, the 
traditional importance assigned to lineage tends to structure high-fertility norms, ${ }^{42}$ economic institutions allocate land, wealth, and access to social influence according to family size, ${ }^{43}$ and social institutions associated with polygyny, in turn, tend to weaken the conjugal bond and constrain spousal communication. ${ }^{44}$ Most social scientists argue that pronatalist beliefs and customs are so ubiquitous and ingrained in society that African social institutions weaken the efficacy of family planning services. ${ }^{45}$

The demand constraints on program impact are further complicated by turbulent economic, social, and political circumstances throughout the sub-Saharan region. Economic analyses show that widespread poverty in the region would constrain programs even if social conditions were favorable to family planning (Sowa and Ohadike 1989). ${ }^{46}$ Deteriorating economic conditions have further complicated the task of organizing effective service agencies in many countries. Moreover, in much of rural Africa, the role of secondary institutions such as political, bureaucratic, or governmental organizations is weaker than the role of primary institutions such as clan, kin, extended family, and other traditional social groups. As secondary institutions, family planning organizations are often ill-equipped to organize programs that are truly community based. The extent to which CBD can succeed often depends upon the strength of the strategic link between primary and secondary institutions - a difficult organizational task in the African context. Public-sector ministries around the world are notoriously inept at establishing community links. In Africa, this task is particularly daunting but particularly crucial for establishing effective community programs.

Even under favorable social and institutional circumstances, the challenge of organizing effective family planning programs in the region would be complicated by health conditions. Of the developing regions, tropical Africa has by far the highest mortality rates among children, the highest maternal mortality rates, and the highest incidence of infectious disease. Research on the implications of high mortality for fertility is not conclusive, but most social theorists assign central significance to the role of high mortality in shaping high-fertility norms. ${ }^{47}$ 
Too often, programmatic research is designed as if demand-side constraints to successful $\mathrm{CBD}$ are inconsequential. Much could be gained from applying social research methods to CBD strategic issues. ${ }^{48}$ Table 4 lists selected social

Table 4 Illustrative agenda for applied social research on the climate of demand for family planning

\begin{tabular}{|c|c|c|}
\hline $\begin{array}{l}\text { Social research } \\
\text { finding }\end{array}$ & $\begin{array}{l}\text { Possible consequence } \\
\text { for family planning }\end{array}$ & $\begin{array}{l}\text { Questions or issues for } \\
\text { applied research }\end{array}$ \\
\hline $\begin{array}{l}\text { Strong emphasis on } \\
\text { lineage; social and } \\
\text { cultural high-fertility } \\
\text { values }\end{array}$ & $\begin{array}{l}\text { High social costs of family } \\
\text { planning; weak social } \\
\text { support for program } \\
\text { activities; concerns about } \\
\text { privacy }\end{array}$ & $\begin{array}{l}\text { Can social structure provide an } \\
\text { organizational basis for CBD? } \\
\text { How should agent selection, } \\
\text { supervision, and management } \\
\text { relate to community leadership } \\
\text { organization, and structure? } \\
\text { How can the program work with } \\
\text { opinion leaders or influential men } \\
\text { and women at the village level? } \\
\text { How are opinion leaders } \\
\text { appropriately involved in CBD? }\end{array}$ \\
\hline $\begin{array}{l}\text { Weak conjugal bond; } \\
\text { segmented economic } \\
\text { roles }\end{array}$ & $\begin{array}{l}\text { Poor spousal communication; } \\
\text { weak climate for joint } \\
\text { decisionmaking; concerns } \\
\text { about infidelity; concerns } \\
\text { about confidentiality }\end{array}$ & $\begin{array}{l}\text { How is outreach best organized } \\
\text { for men? How is confidentiality } \\
\text { best assured? } \\
\text { What can be done to foster } \\
\text { spousal communication, joint } \\
\text { decisionmaking, and mutual } \\
\text { confidence in the benefits } \\
\text { of family planning? }\end{array}$ \\
\hline $\begin{array}{l}\text { Perceived economic } \\
\text { benefits of children; } \\
\text { low economic costs } \\
\text { of childbearing }\end{array}$ & $\begin{array}{l}\text { Low levels of demand for } \\
\text { limiting fertility }\end{array}$ & $\begin{array}{l}\text { How is child spacing best promoted? } \\
\text { How can the social, psychological, } \\
\text { and familial costs of contraception } \\
\text { be reduced with CBD? } \\
\text { Who in society creates constraints } \\
\text { to fertility regulation, and how } \\
\text { can they be approached with } \\
\text { effective outreach? }\end{array}$ \\
\hline $\begin{array}{l}\text { High mortality risks, } \\
\text { particularly among } \\
\text { children }\end{array}$ & $\begin{array}{l}\text { High-fertility aspirations; } \\
\text { prevalent health concerns; } \\
\text { desire for family planning to } \\
\text { be integrated with health and } \\
\text { maternal and child health } \\
\text { services }\end{array}$ & $\begin{array}{l}\text { How can health and family } \\
\text { planning outreach be combined } \\
\text { without diminishing the } \\
\text { operational importance of family } \\
\text { planning activities? }\end{array}$ \\
\hline
\end{tabular}


research findings, their possible consequences for family planning, and questions for programmatic research. Focus-group discussion of fertility determinants, family planning implications, and possible research issues would be a productive exploratory mechanism for directing inquiry into the issue of constrained demand. Not all issues can be resolved in this fashion, but social research could be useful for identifying questions that operations research might resolve. ${ }^{49}$

\section{LeSSONS FROM Four NATIONAL CBD PROGRAMS}

Evidence concerning the determinants of CBD success or failure emerges from a variety of sources including case studies of large-scale activities, operations research pilot studies and field projects, and specific studies of management issues in CBD. CBD programs in Africa provide strategic contrasts that merit review.

\section{The Kenya Experience}

Kenya has the greatest diversity in CBD programs and activities of any country in the world. In the 1980s, CBD initiatives proliferated with the encouragement and support of the National Council for Population and Development and financial support from the Kenya USAID Mission (see Division of Family Health, Ministry of Health et al. 1991). Rather than standardizing a centrally planned initiative, official policy has encouraged action in diverse private- and public-sector organizations. In some agencies, coverage is achieved by canvassing, in others by community depots, and in others by distribution through village women's groups. In some programs, workers are volunteers; in others, paid personnel; and in others, compensated volunteers. The level of compensation also differs considerably by agency. Recruitment and training schemes differ, and administration, logistics, supervision, and management information systems follow no set scheme or unified design. In a genuine sense, Kenya represents a laboratory of CBD diversity in that nearly every type of CBD approach that has been tried anywhere is represented in some fashion in the Kenyan setting. ${ }^{50}$ 
A comprehensive comparative analysis of seven of Kenya's major CBD programs has concluded that no one program was strongest or weakest in all elements (Chege and Askew 1997). Various reviews and evidence suggest, nonetheless, that CBD is feasible and effective in a variety of contexts, and service statistics attest to a considerable volume of CBD services. Most commentators agree that this operational diversity has been a resource rather than a hindrance to CBD development in Kenya and that nothing would be gained by standardizing CBD approaches across agencies (see Phillips and Kiragu 1998).

Survey responses suggest that CBD informs many couples about family planning in Kenya and that CBD may, therefore, contribute incrementally to contraceptive use. ${ }^{51}$ Moreover, statistical analyses have been completed suggesting that CBD programs in Kenya have accelerated a demographic transition that was initiated by social and economic forces (Hammerslough 1991 and 1992).

The main lessons from Kenya are that a variety of approaches can work and that strategic consistency within approaches is important to success. Figure 5 illustrates operational elements of successful CBD agencies. Type I programs are typically centralized and highly focused organizations that are staffed at the pe-

Figure 5 Elements of strategic consistency in the Kenya CBD effort

\begin{tabular}{|l|l|}
\hline \multicolumn{2}{|c|}{$\begin{array}{c}\text { Type I } \\
\text { Single purpose } \\
\text { Centralized (top down) } \\
\text { Volunteer workers }\end{array}$} \\
\hline \multicolumn{2}{|c|}{ Type II } \\
$\begin{array}{ll}\text { Single purpose } \\
\text { Centralized (top down) } \\
\text { Paid (successful) } \\
\text { Unpaid (unsuccessful) }\end{array}$ & $\begin{array}{l}\text { Type III } \\
\text { Multipurpose } \\
\text { Decentralized (bottom up) } \\
\text { Voluntary }\end{array}$ \\
\hline
\end{tabular}


riphery by unpaid volunteer workers. This kind of program works because volunteers' time contributions can be linked to activities that they normally engage in, even in the absence of the program. Type II programs require workers to follow set schedules, canvass villages, and engage in routine tasks that require paid professional staff. Type III programs marshal community leadership or integrate CBD into political activities. For this reason, Type III CBD tends to be integrated into the non-family planning activities of women and multipurpose development agencies. Where a strong "bottom-up" mandate and organizational capacities exist for motivating informal workers to perform CBD duties, volunteer CBD programs have worked well..$^{52}$ Political organizations are structured in this way; church organizations also generate dedicated volunteerism. In some instances, charismatic leaders have created development or health-service systems that generate a context in which volunteerism works (see Phillips et al. 1992). In the absence of a strong motivational backbone, however, the viability of volunteer worker schemes is doubtful..$^{53}$

\section{Type I CBD in Nigeria}

Nigeria provides lessons from market-trader examples of Type I CBD effort. In 1985, the University of Ibadan launched a feasibility study to test the acceptability of training and equipping traditional market vendors to sell contraceptives in 39 markets of Ibadan City (for example, see Iyun et al. 1985, 1987, and 1988; Webb 1987a, 1987b, 1988, and 1989; and Peters de Folch Lyon 1985). This approach to family planning service delivery has since proliferated in Nigeria and now encompasses several distinctly different schemes for training and equipping traditional market traders to add contraceptive commodities to the items that they sell (for example, see Ladipo et al. 1986 and 1990; Lambo et al. 1990; Kwara State Ministry of Health 1990; Lagos Study Team 1986; Delano 1987; Jugan and Schellstede 1986; and Masha 1987). The commercial sale of contra- 
ceptives in market locations is based on the premise that making services available in markets will increase contraceptive awareness and use (Ladipo et al. 1990).

Considerable international attention has been directed to this initiative, in part because it uses the traditional African institutional arrangements of the market to foster family planning, and in part because it is potentially a self-sustaining, low-cost mechanism for reaching a large segment of society (see Jinadu et al. 1993). The underlying hypothesis of the approach can be stated as follows: Shoppers who are exposed to accessible, low-cost family planning supplies in markets are more likely to use a method than are shoppers who are not exposed to convenient supplies. Despite the apparent potential of this approach, no evidence exists from the Nigerian experience to support the basic CBD hypothesis. No evidence has emerged that traditional market sales of contraceptives improve the acceptability, efficacy, or quality of family planning in areas served by this approach. Gross sales data have suggested that the impact of the strategy may be confined to an initial introductory period, after which sales decline. ${ }^{54}$

A 1993 review of 14 separate vendor initiatives revealed that traditional market trading networks, pricing practices, and logistical arrangements have not been used by the program (Jinadu et al. 1993). Despite project claims that traditional market mechanisms are used, most trader organizational arrangements have been structured as nontraditional family planning agencies. For this reason, the institutionalization of market-vendor schemes has not worked well in the past. ${ }^{55}$ Well-managed and rigorously implemented market-vendor schemes likely could succeed, however, and implementation problems could probably be resolved through basic research (see Jinadu et al. 1993).

A 1998 evaluation suggested that agents in market-based programs were used by half of the market-going population, although impact on contraceptive prevalence was not known (Weiss 1998). That evaluation concluded that market projects were easier and cheaper to manage than were other CBD projects in Nigeria, and called for research to determine the optimal density of market agents. 


\section{Type II CBD in Zimbabwe}

Zimbabwe provides an example of Type II public-sector program implementation and sustainability with a national community-based distribution program that has been in operation since 1983. The program is administered by the Zimbabwean National Family Planning Council, a parastatal agency, and its objectives are to make modern contraceptives available to people through household distribution, educate them about family planning, recruit new acceptors, follow up on dropouts, and make referrals to health centers when necessary. Zimbabwean distributors are selected by the communities served, receive government salaries and benefits, and are assigned a defined catchment area in which they are expected to complete rounds of household visits in three-week cycles (see Muvandi 1990; Zimbabwe National Family Planning Council 1990; and Dube et al. 1998). A large national information campaign promotes family planning with messages targeted to various population subgroups, most prominently to men (see Kuseka et al. 1990).

In 1988, modern contraceptive prevalence was 36 percent and traditional contraceptive methods were measured at 7 percent. The Zimbabwean total fertility rate (TFR) declined from 6.5 children per woman of reproductive age to as low as 5.3 children between 1984 and 1988. By 1994, it had reached 4.3. ${ }^{56}$ The role of CBD in producing the rising contraceptive prevalence rate has been the subject of considerable discussion and debate, however. The debate centers around three issues:

First, the nature of reproductive change in Zimbabwe has required clarification, because the rise in prevalence has not translated into a pace of fertility decline that is consistent with relationships observed elsewhere. Despite the rapid increase in contraceptive prevalence to more than 40 percent of the eligible population, Zimbabwean fertility decline has been less than anticipated.$^{57}$ The adoption of contraception for spacing and the extensive substitution of contraception for other proximate fertility determinants apparently explain the slower-than- 
expected pace of fertility decline. ${ }^{58}$ Substitution of contraception for traditional fertility control introduces an element of uncertainty about the impact of CBD and family planning in general on fertility.

Second, geographic variance in contraceptive use bears no relationship to CBD activity. ${ }^{59}$ This finding may be a result of statistical biases arising from policies assigning $\mathrm{CBD}$ agents to remote, low-prevalence areas. Also, CBD may not be as effective in increasing contraceptive use as in expanding clinical services.

Third, the sheer size and cost of the Zimbabwe CBD program are controversial. The national program bureaucracy represents an expensive commitment. Nevertheless, survey data suggest that distributors play a minor role in the provision of supplies to new acceptors and may not be crucial for resupplying purposes. ${ }^{60}$ The 1991 and 1996 Zimbabwe Situation Analysis Studies revealed that clients were willing to obtain their supplies from a depot-holder instead of a CBD agent, allowing agents to focus their efforts on recruiting new clients. This Type I depot model has been piloted, and situation analysis results suggest that it should be expanded (Dube et al. 1998).

The assumption that CBD has been a factor in the Zimbabwe story is a reasonable one, but beyond anecdotal evidence, little can be said about the demographic role of CBD in Zimbabwe. ${ }^{61}$ The Zimbabwe case suggests that a fairly unimaginative top-down, Type II bureaucratic approach to CBD may have worked. Reports advocating this view attribute success to selecting workers from the villages they serve, paying them a regular wage, assigning them clearly defined tasks, and holding them accountable for performing a basic work regimen that is easy to understand and feasible to carry out (see Nzuma 1986; Mugwagwa 1989; Zihanga 1990; and Guilkey and Cochrane 1992).

\section{Type III CBD in Ghana}

CBD programs in Ghana illustrate the benefits of using social research findings to guide program priorities. In 1969, Ghana became the second country 
in Africa (after Kenya) to promulgate an official population policy. Failed effort in Ghana illustrates the value of evidence-based policy planning.

Early in the Ghana program, organizers assumed that accessibility to services would be the crucial problem to solve in developing CBD. Because midwives and traditional birth attendants (TBAs) are accessible to women throughout the country, the Ghana Registered Midwives Association (GRMA) Family Planning Program was assigned the task of midwife training and field coordination of a family planning initiative. This initiative was subsequently expanded by training TBAs to provide family planning services as a CBD program. A national CBD project was constituted to identify TBAs, upgrade their delivery skills, and train them in the sale and distribution of pills and condoms.

In terms of numbers of people trained and volume of contraceptive sales, the midwife-TBA approach appeared to be successful (Ghana Registered Midwives Association 1990). However, survey data eventually revealed that the volume of contraceptive distribution among midwives and TBAs remained low. The Ministry of Health estimated that a TBA, on average, supplies fewer than ten clients a year with contraceptives.

In response to this finding, the Ministry of Health fielded a series of focusgroup studies designed to elicit community opinion about the program and to garner advice on how to improve CBD acceptability. Results of this investigation showed that accessibility was not the primary concern of villagers. Other costs enumerated earlier by Easterlin were of greater concern (see Ministry of Health, Health Research Unit 1991a-c and 1992). Uneasiness about lack of privacy and confidentiality led to objections about the choice of midwives and TBAs as contraceptive distributors. TBAs were viewed as socially gregarious individuals who talk openly about who is using family planning. This finding suggests that such preselection of agents is not acceptable in Ghana, because the persons chosen do not have the ability to keep secrets or other personal qualities that engender trust. The trustworthiness of agents was considered to be more important than any 
other trait (Ministry of Health, Health Research Unit 1991a-c). The focus on contraception to the apparent detriment of health concerns also weakened the program. The TBA experience in Ghana attests to the hazard of premature program development. Even a seemingly sound idea merits trial and investigation before large-scale CBD operations are fielded.

In 1994, the Navrongo Health Research Centre launched a new CBD experiment in northern Ghana in response to the failure of the national TBA agent CBD program..$^{62}$ The experiment demonstrated that community participation in the design of CBD is feasible. With guidance from social research, Type III CBD in the Navrongo experiment produced a change in contraceptive practice in a region where such results were once considered unattainable. The Navrongo experiment is a trial of a process for developing optimal services rather than a test of a particular CBD strategy. The key to success in Navrongo has been designing culturally sensitive approaches for providing services to women and information to men. This approach involved a program of participatory learning in pilot villages and of large-scale experimentation on alternative CBD models (see Nazzar et al. 1995). Research has shown that the total fertility rate dropped from 5.4 children per woman of reproductive age to 5.0 children in three treatment areas, whereas fertility remained unchanged in the comparison areas. Reported contraceptive use increased in all treatment areas relative to controls, but the precise extent of this impact is unknown because survey respondents are often deceptive about contraceptive use. ${ }^{63}$ Focus-group data from the Navrongo experience suggest that broad-based health-service approaches are needed in settings where mortality is high and demand for family planning is weak. Demographic research lends support to the hypothesis that CBD reduces fertility even in traditional Sahelian Africa. This impact occurs irrespective of the CBD strategy used. In summary, the experience of CBD in Kenya, Nigeria, Zimbabwe, and Ghana has revealed three themes that may have relevance to other countries in Africa. 
First, predetermined CBD strategies typically are feasible to implement, but often are not the most appropriate approaches for a particular setting. As the Ghana experience demonstrates, CBD strategies should be tested and adjusted to local conditions before large-scale operations are implemented. Strategies for managing $\mathrm{CBD}$ in one type of institutional environment may not be appropriate for another organizational environment. For this reason, systems for CBD must be assessed in the broader organizational setting where outreach services are based. If these precautions are taken, and if programs are pursued with political resolve and ample resources, imported CBD models like that used in Zimbabwe may be made to work.

Second, no single model emerges as the optimal universal approach to CBD. The Kenyan decentralized strategy has encouraged diverse approaches through a variety of institutions. By fostering the proliferation of NGOs, the Kenyan program established de facto centralization and marshaled resources for the program that would not have emerged otherwise.

Third, mixed models do not work. In Zimbabwe, a bureaucratic, top-down CBD program was successfully implemented. As demonstrated by the Kenyan Ministry of Health, however, bureaucratic, top-down models should not be used with attempts to provide CBD services through volunteers. African organizational approaches can work well, but not as appendages to artificial public bureaucracies. If a program is organized on African institutional principles, the logic of indigenous networks, structures, and systems of interchange must be thoroughly understood and fully employed.

\section{LESSONS LEARNED FROM CBD SUCCESS AND FAILURE}

In general, the CBD literature is diffuse and atheoretical, complicating the task of deriving cross-cultural themes or generic lessons. Research findings and management reviews of CBD programs and pilot projects throughout the sub- 
Saharan region suggest certain general conclusions about basic management, however, that can improve service delivery and ultimately lead to greater impact on contraceptive prevalence or total fertility.

\section{Elements of Successful CBD Management}

Operational diversity in CBD activities derives from alternative approaches to the CBD service regimen; to community involvement; to agent selection, training, compensation, and supervision; to the manner of deployment; to the resource base for salaries and operational costs; to management information systems; and to political support. Experience with CBD in Africa has provided information about which approaches and combinations of approaches are most successful (see Table 5).

The service regimen of CBD programs is sometimes highly focused on family planning and sometimes integrated with primary-health-care outreach. Ever since the 1994 International Conference on Population and Development in Cairo, increasing attention has been directed to integrating reproductive health activities into CBD schemes. Extending multiple service options is generally believed to improve service quality and acceptability, and offering contraceptive methods and services in conjunction with other health services tends to enhance the credibility of family planning. Broadening the service regimen adds management challenges that must be addressed in careful strategic planning, however. Broadening CBD programs to include reproductive health requires extensive training programs. For example, situation analysis in Zimbabwe has shown that CBD agents know few of the signs and symptoms of sexually transmitted diseases (STDs) (Dube et al. 1998). CBD agents may not be the best providers of STD services, because they have to rely upon syndromic management, and nonclinical screening methods are known to be ineffective. ${ }^{64}$

Community leaders can be involved in $\mathrm{CBD}$ as the collective recipients of information, the coordinators of information and educational activities, or as di- 
Table 5 Elements of effective CBD management

Element

Service regimen should be as

broad as possible.

Community involvement is crucial at the strategic planning stage.

CBD agent selection should be guided by community opinion rather than by predetermined criteria.

$C B D$ agent deployment should use traditional social or economic networks as a convenient basis for reaching village groups.

Agent compensation

Paid workers perform better than volunteers.

If workers are unpaid volunteers, the deployment scheme should not be demanding.

Completely voluntary schemes do not work well. If workers are not paid, some other motivational scheme is required.

CBD agent training should be based on competence and be incremental and practical.

CBD agent supervision should be supportive rather than directive.

Management information systems should support the informational needs of CBD agents as a first priority. Information for senior management can be aggregated as needed.

Political support for family planning generally is not obviated by launching CBD programs.

\section{Reference}

Jain et al. 1992; MoH, Social

Solidarity and the Aged, and the Population Council 1993; Projet des Services des Naissances Désirables, Division de la Recherche Opérationnelle and the Population Council 1991

Nazzar et al. 1995; Phillips and Greene 1993. See also Askew and Khan 1990; Delano 1990; Kaseje et al. 1987b; and Mukolwe et al. 1990 Gallen and Rinehart 1986; Zinaga 1990. See also Population Reference Bureau 1987

Phillips and Greene 1993

El Tom et al. 1987 and 1989; Gallen and Rinehart 1986; MoH, Social Solidarity and the Aged, and the Population Council 1993; Ministry of Public Health Directorate of Family and Mental Health and the Population Council 1993; Pooley et al. 1989; Primary Health Care Directorate and Center for Population and Family Health 1989. For lessons in CBD agent compensation from Zaire, see Division of Family Health et al. 1991; Kuwana 1989; and Penn 1989

Gallen and Rinehart 1986

Keyonzo et al. 1989a. See also Department of Community Medicine and Center for Population and Family Health 1988; Foreit and Foreit 1984; Motlomelo et al. 1990; and Phillips et al. 1992

Bernhart 1991; UNFPA 1990

Lauro et al. 1991; Office Nationale de la Population and Center for Population and Family Health 1989 
rect managers of CBD operations. Alternatively, traditional leaders and social groups can be involved in all aspects of CBD planning, management, and implementation. Models for community involvement are thus highly varied. Community involvement is crucial at the strategic planning stage. Leaders can participate effectively in the design of operations, but are less effective in implementation or routine management.

CBD agent selection is a key variable in program design. Agents can be selected by the community or chosen by a sponsoring program. Experience generally shows that community selection of agents is more effective than is setting predetermined criteria for agents. Seeking an internationally optimal type of agent is fruitless. Operations research can demonstrate practical means for identifying the appropriate type of agent, but they should not be used to test the efficacy of some predetermined category of service worker.

CBD agents can be uncompensated or compensated for their work. Paid distributors, in turn, are sometimes compensated in cash or with other forms of reward. Rewards in cash can derive from user fees, community insurance schemes, or direct payments as wages. The research record generally shows that paid workers perform better than volunteers. When agents are paid, rigorous supervision can be exercised, programs can be implemented rapidly, work routines can be standardized and designed to cover populations, and service quality can be maintained. Research also shows that when workers are unpaid volunteers, the deployment scheme should not be demanding and that some other motivational scheme is required to substitute for the absence of wages. Voluntary CBD programs are more complex to manage than are programs that rely upon paid agents. Type II approaches require paid workers; Type I models sometimes work well with unpaid agents. ${ }^{65}$

The appropriate type of agent deployment is dictated by the CBD strategy used. Type I programs use a static strategy whereby supply depots are staffed by 
agents and placed in convenient village locations. Type II programs assign workers to geographic areas and instruct agents to visit households methodically and sequentially. A Type III approach uses traditional social or economic networks as a convenient basis for reaching village groups and legitimizing CBD. Distribution agents may be deployed to places where men or women congregate for nonfamily planning purposes (for example, markets, women's associations, or other village social functions) as well as to people's homes. As noted above, the common assumption that accessibility is the primary constraint to contraceptive use has not been demonstrated by research. Social costs represent the most important set of constraints, and some evidence suggests that social discord may arise from failing to address social impact issues. Men's fears and concerns that lead to social costs for women can be addressed with appropriate male mobilization strategies.

CBD agents can be trained in clinical methods or village diplomacy or both. In Africa, experience shows that broad-based social and technical training is preferable to narrow technical design. The frequency of in-service training varies widely among projects, although most observers agree that the quality and intensity of agents' training is the most important single determinant of program quality and impact. Training of CBD agents should be based on competence and be incremental and practical.

Models for agents' supervision vary considerably. In some programs, supervisors are paid professionals, whereas others use volunteers. In general, effective supervision requires professional staff. When village workers are volunteers, supervising challenges increase, because community activities must be designed to motivate workers and clients alike. Styles of supervision differ therefore, according to the field strategy used and the institutional culture of the CBD agency. Whatever the approach, supervision should be supportive rather than directive. Supervisors recruited from the ranks of CBD agents are more effective than are hired supervisors who have no service-delivery experience. 
Ever since family planning programs were first organized, information systems have been designed to provide indicators on performance. CBD represents a unique challenge to management information systems design, because systems must be simple to use and yet informative. Information systems should support the quality-of-care information needs of CBD agents as a first priority. Information for senior management can be aggregated as needed. Systems designed to extract information solely for senior management do not work.

In Africa, considerable emphasis has been placed on developing costrecovery schemes for $\mathrm{CBD}$. The typical scheme charges commodity fees to users and awards a percentage of this fee to agents. In some projects, however, community health-service systems have been developed with cost-recovery mechanisms for primary-health-care services. Health-service fees can generate revenue to subsidize family planning CBD indirectly. ${ }^{66}$ In several West African countries, revenue from dispensing essential drugs is used to finance health outreach. ${ }^{67} \mathrm{Com}-$ munity-financed schemes are still in the planning or pilot stage, however, and have proved to be complicated to organize and difficult to manage, perhaps because they have not been tested and researched adequately. When demand for family planning is fragile, cost-recovery schemes often face fundamental organizational challenges.

Removing service from the confines of clinics subjects programs to political requirements at all levels-national, regional, and local. CBD effort often involves careful liaison with political authorities. Launching a CBD program does not obviate the need for political support for family planning more generally. Several important trials have demonstrated the critical role of political support for CBD.

\section{Factors Contributing to CBD Failure}

A CBD project can be considered successful if it introduces family planning to a population and the introduction results in higher levels of contraceptive use than would be expected in the absence of $\mathrm{CBD}$, or if it enables women to 
attain their reproductive goals more effectively. Reasons for failure typically are not discussed in reports, because projects often have the modest goal of demonstrating operational feasibility rather than of establishing that the project's strategy has worked. Several studies and large-scale programs have clearly failed to confirm hypotheses about the role of CBD. ${ }^{68}$ Common reasons for CBD program failure are discussed below.

Misplaced faith in CBD success can lead to failure if planners view CBD as something that is simple and automatically so successful that the basic elements of service quality and sound management are neglected (see Motlomelo et al. 1990). Although endlessly repeated trials of CBD impact are not necessary, the process of developing large-scale optimal CBD operations is likely to require organizational research in each setting where a new CBD program is launched. Considerable progress has been registered since techniques of evidence-based organizational development were developed in the 1960s (Lawrence and Lorsch 1969; Bennis 1969; Beckhard 1969; French and Bell 1978). This approach emphasizes the importance of developing strategies that fit the organizational environment, testing and developing pilot approaches on a small scale, and phasing in change in large-scale operations ${ }^{69}$ Premature implementation sometimes weakens CBD programs because large-scale effort is inappropriate for the social environment. Mixing the elements of different CBD models sometimes weakens strategic designs. For example, as noted above, when a bureaucratic, top-down program attempts to use volunteer CBD agents, the results are often unsatisfactory (see Ferguson 1998). Research, therefore, has renewed benefits for each site where CBD is tried. The main pitfall of premature CBD implementation is failing to use strategies that are guided by community opinion (see $\mathrm{MoH}$, Health Research Unit 1991a-c).

Preoccupation with a single good idea can direct attention away from developing a comprehensive service system. When $\mathrm{CBD}$ fails, its failure has less to 
do with what is being tried than with the absence of other critical elements of comprehensive service systems. ${ }^{70} \mathrm{CBD}$ research should be driven less by discrete questions about the relative impact of contrasting operational design than by the need to adopt and develop a CBD system of care that is appropriate for a particular setting. CBD fails, not because the specific operational ideas pursued are flawed, but because a system of care has not been developed in which the full potential of a set of good ideas can be realized. ${ }^{71}$ The operational design of the program should be guided by the organizational design of social institutions. ${ }^{72}$

CBD can fail if the initiative has narrow institutional grounding. For example, a failure to build political support can lead to CBD failure. Local political resistance or administrative objections and lapses can arise from a weak commitment to population issues. Strategies for building family planning commitment should be a theme of CBD research (see Bertrand et al. 1993, Office National de la Population 1989, McGinn 1989, and McNamara et al. 1992).

Premature focus on sustainability and cost recovery can weaken CBD effort. Community volunteer agents, community financing, and user fee schemes have not worked well (see Agyepong and Marfo 1992). In Africa, where demand for family planning is often fragile, sustainability schemes introduce new operational complications and user constraints. Sustainability represents a second-generation issue in the design of programs. Expensive, heavily subsidized professional programs may be more sustainable than alternative designs simply because they may introduce the concept of reproductive planning effectively and launch transitions that produce self-sustaining demographic change in the long run (see Cleland et al. 1994).

Failure to address quality-of-care requirements and social costs can weaken programs. CBD is sometimes implemented quickly without adequate attention to quality of care or possible social costs. ${ }^{73}$ Evidence gained from pilot studies can be crucial to diagnosing quality-of-care problems before large-scale CBD operations are instituted. 


\section{CONCLUSION}

More than two hundred papers are available concerning CBD activities in Africa, many representing evaluations of pilot projects and demonstrations aimed at fostering future action. Although much has been achieved and documented in the CBD literature, important issues and challenges remain:

CBD research is based on the view that policies should be founded on the evidence of results. Nevertheless, extracting general lessons from the CBD research record is difficult. To a significant degree, this problem is inherent in research on the setting. Africa is the world's most culturally diverse region, and its countries are ethnically complex. ${ }^{74} \mathrm{CBD}$ extends programs from the controlled and artificial environment of clinics to diverse social environments that structure life in the home, village, market, or workplace. CBD research designs are thus repeated on a scale that has not been required in Asia or in Latin America. But the generalizability of findings is also impeded by the inattention to theory in CBD research. Research is often site specific and particular rather than guided by theories that can be tested and used to clarify general principles for tailoring strategies to the social environment. Although nonclinical strategies have been critical to the success of many family planning programs, achieving optimum results involves adapting the approach to the social setting. Cultural zones with varying contraceptive prevalence and religious and cultural practices will require specifically tailored CBD programs. ${ }^{75}$ As Africa becomes more urban, CBD must be modified and developed to reflect this shift. For the foreseeable future, social research will represent an essential tool for adapting CBD program design to the social environment where operations are implemented.

Trials and demonstrations of CBD often begin with operational designs that are contrived by researchers, rather than developed as an outcome of diagnostic investigation. This predesigned approach can lead to premature specification of what is to be tested, who will provide services, how workers will be compen- 
sated, how organizations will be structured, and other overriding strategic issues. $\mathrm{CBD}$ may be more easily adaptive to settings in which more attention is consigned to diagnostic studies of what service designs communities want and how implementation should be organized ${ }^{76} \mathrm{CBD}$ programs could derive practical benefit from the application of open-systems organizational theory to the process of strategic planning: Research on traditional social organizations and social institutions that influence reproductive behavior is highly relevant to the goal of improving the functioning of CBD programs in constrained settings. ${ }^{77}$

Research efforts must also be geared toward understanding CBD failure. Lessons that could be learned from failed CBD programs are often lost or buried because of the tendency to publicize only successful programs. However, each CBD effort that failed can generate insights into what might work. More comparative analysis of success and failure is needed so that CBD policy is guided by the full range of experience with this strategy. ${ }^{78}$

Failure sometimes arises from well-intentioned but poorly researched costrecovery policies. Launched in the name of achieving sustainability, user fees and cost-recovery schemes can represent a serious constraint to program implementation. If a nonsustainable program introduces family planning and fosters reproductive change in a setting where demand is fragile, the demographic transition emerging from this effort may become demand driven in the long run. Thus, in Africa, short-term investments in nonsustainable CBD costs may eventually produce self-sustaining reproductive change. ${ }^{79}$

Important gaps in CBD research are currently being addressed by donor and research agencies. The feasibility of extending CBD services to include reproductive health is unclear because research has shown that syndromic screening does not work and that clinical testing is crucial to effective diagnosis and care of sexually transmitted diseases and reproductive tract infections. Thus, when broader reproductive health services have been added to CBD programs, effects 
on reproductive health are unknown. Until technology for nonclinical screening is developed, village workers will not contribute significantly to reducing morbidity from infectious disease. Moreover, other components of CBD reproductive health impact merit investigation. For example, no study has demonstrated that $\mathrm{CBD}$ reduces abortion rates or improves maternal health or survival.

\section{Implications of CBD research}

Despite the limitations of the CBD research record, some important conclusions have emerged from CBD studies. First, CBD is clearly administratively feasible, even in settings where contraceptive use is low. Social research has often demonstrated constrained demand for family planning in sub-Saharan Africa. No evidence has shown, however, that constrained demand impedes the implementation of services if precautions are taken to insure that the approaches used are culturally sensitive and that the services provided are of the highest possible quality.

Second, evidence suggests that social accessibility represents a more important determinant of CBD impact than geographic accessibility. For this reason, male outreach, community mobilization, use of women's networks, and other strategies involving social organizations may be more important to the success of CBD efforts than is the simple provision of accessible supplies.

Finally, studies in Burkina Faso, the Gambia, Ghana, Kenya, and Mali testing the CBD hypothesis with quasi-experimental designs have demonstrated that $\mathrm{CBD}$ efforts make contributions to contraceptive use that would not otherwise occur. CBD appears to foster reproductive change in settings where contraceptive use is low and health services are inaccessible ${ }^{80}$ Integrating CBD into other health services appears to be more acceptable than designing vertical programs, but even vertical programs can work. Although the precise fertility implications of this contribution are as yet untested and unknown, CBD will likely be 
shown to contribute to demographic change in a variety of settings. As the nature of the demographic role of $\mathrm{CBD}$ is clarified, shifting the research agenda to replicate CBD pilot project successes, discovering the determinants of CBD efficiency, and testing means of adapting strategies to social needs will all be important. Shifting the agenda to second-generation issues will require that more attention be paid to optimal CBD development. Impact studies and discrete operational research should be conducted in the context of general frameworks for scaling up results, changing institutions, and reforming policies on the basis of lessons learned.

\section{Notes}

1 In Ghana, nurse-midwives have been trained to provide family planning services in private maternity homes (Center for Population and Family Health 1989). Although this approach is more clinical than nonclinical, it illustrates the fact that nonclinical approaches are not always distinct from clinical strategies. Variants on this strategy have been tried in programs in Bangladesh, Egypt, India, and Kenya.

2 As Lewis et al. (1992:1) note, CBD programs are "designed to work through the grassroots level infrastructure of communities, tapping local resources and enlisting community members as CBD workers to provide the services." As Kols and Wawer (1982:L-77) state, CBD focuses on "common and important health problems of the community, health problems for which there are effective remedies, services and supplies that are relatively safe and easy to deliver."

3 In Asian programs, injectables, Norplant ${ }^{\circledR}$, and IUDs are provided in largescale nonclinical projects. 
4 The integration of HIV/STD prevention and family planning activities is increasingly common and necessary. See Musau (1997) for discussion of Uganda's Busoga Diocese Family Life Education Project; Family Planning Association of Kenya and the African OR/TA Project (1995), and Anonymous (1995) for discussion of integrated CBD programs in Kenya; and Projet des Services des Naissances Désirables and Tulane University (1993) for discussion of integrated CBD in Zaire. This approach is an alternative to targeted interventions that focus prevention efforts on specific groups rather than on the community as a whole (D'Cruz-Grote 1997).

5 An early project in Ghana used a mobile clinic and village health post approach (see the description of the Danfa Family Planning Program in Ghana by Nicholas 1978). Variants on this theme have been successful in Latin America (for example, in Paraguay and Ecuador; see Foreit et al. 1991), and in Indonesia where the strategy was first developed (Anonymous 1976; Warwick et al. 1983).

6 See reviews of projects in Zaire (Bertrand et al. 1986 and 1993); Indonesia (Anonymous 1976); Bangladesh (Koblinsky et al. 1986); and elsewhere (Ross et al. 1987).

7 In the 1980s, the Zimbabwe National Family Planning Council employed 668 workers to provide community-based family planning services (Zinanga 1990). The approach is similar to CBD models in South Asia (see, for example, Koblinsky et al. 1986; and Simmons et al. 1988).

8 See, for example, Munyakazi (1989). Variants on this approach have been tried in Gambia, Kenya, Mali, Zaire, and Zimbabwe (Bertrand 1991). 
9 An important distinction exists between CBD that takes place in a market setting and simple social marketing of contraceptives. Market-based CBD programs use market vendors who are not traditionally engaged in pharmaceutical sales to provide CBD at convenient outlets in traditional markets.

10 See Bertrand (1991). In Nigeria, market-trader initiatives have been launched in several large-scale pilot projects (for example, see Ladipo et al. 1990; Fertility Research Unit 1985; and Masha 1987). This approach was subsequently replicated in Ghana (National Council on Women and Development 1990). A review of the various market-vendor initiatives in Nigeria appears in Jinadu et al. (1993). The 1990s have seen numerous contraceptive social marketing initiatives in Africa. Some programs train market traders as CBD agents and some focus efforts on advertising and distribute contraceptives through pharmacies. The latter are not considered part of the CBD effort. Numerous reviews of African social marketing programs are available (for example, Akuetteh 1987; Horn et al. 1992; and Sherris et al. 1985). A 1996 survey in Cameroon found that social marketing was a more effective scheme than free or commercial distribution (Meekers 1997). Success may depend upon the ability of a program to gain the support of male opinion leaders or religious leaders. See Futures Group (1995) for a discussion of this process in Niger and Senegal and Anonymous (1994) for a discussion of Gambia and Cameroon.

11 Experiments with CBD were sponsored by the Thai Ministry of Health in the 1960s (Rosenfield and Limcharoen 1972; Rosenfield et al. 1971) and replicated in neighboring countries in the early 1970s (Foreit et al. 1978). Useful reviews of this experience appear in Ross 1990; Kennedy 1986; Huber et al. 1975; Seewald 1990; and Townsend 1991. 
12 Renewed interest in the determinants of the diffusion of reproductive innovation has been fostered by an insightful review by Cleland and Wilson (1987). The role of social programs in catalyzing social change with community agents is summarized in an early review by Rogers (1973). See also the more general discussion of diffusion theory and the role of outreach in Rogers and Shoemaker (1971).

13 Early experience with CBD in Latin America is summarized in Isaacs (1975). Perhaps the experience of Indonesia with CBD is most relevant to Africa in that community leadership structures were used as the primary organizational units of the Indonesian program. Community volunteers were used rather than civil servants, mobilizing traditional village institutions rather than creating a bureaucracy (see Haryono and Reese 1978; and Lerman et al. 1989). Several authors have noted that social structure and cultural norms should be considered in the design of family planning programs (see, for example, Warwick 1988; Warwick et al. 1983; and Aryee 1989). Possible links to links to women's groups have been discussed in the literature (see, for example, Hammerslough 1991 and 1992), but CBD programs more typically use nontraditional systems, such as nongovernmental organizations or public-sector bureaucracies. Interesting exceptions exist in Africa. The highly successful Chogoria project was developed as a component of a long-standing church outreach program with unusual organizational strengths for extending health services to the community (Goldberg et al. 1987 and 1989). Other applications of this approach have been less successful, however, and its programmatic implications are thus unclear (see, for example, Labbok et al. 1985; and Labbok and Shah 1988). More in keeping with the Indonesia model are the special projects in Kenya that link family planning with women's self-help groups (see Maendeleo 
ya Wanawake Organization 1991 and Makindu 1986). The efficacy of this approach is unknown, however.

14 Early assessments of the CBD approach can be found in Rosenfield et al. (1971); Atkinson et al. (1974); Rosenfield (1977); Maine (1981); Osborn and Reinke (1981); McGuire (1984); Gray and Labbok (1985); McNamara (1985); Ebo (1986); Rosenfield (1986); and WHO (1986a-d). CBD is also illustrated in Huber and Huber (1975); Wortman (1975); Freedman (1987); WHO (1989); Wolff et al. (1990); Bertrand (1991); and Population Council (1993). For an early discussion of the need for research on CBD impact, see Hauser (1962).

15 In Sierra Leone, this change related to political and social upheavals of the mid-1980s. In Mauritius, an official policy change in 1986 disbanded CBD in response to an official view that the growth rate was "satisfactory" and intensive family planning outreach was no longer necessary (Ross et al. 1992).

16 See the discussion of contemporary demographic transitions in Freedman and Blanc (1991). A comprehensive National Academy of Science review of factors affecting contraceptive use in sub-Saharan Africa has concluded that fertility is declining in Botswana, Kenya, and Zimbabwe and that access to family planning services has contributed to this trend in all three countries (Working Group on Factors Affecting Contraceptive Use, Panel on the Population Dynamics of Sub-Saharan Africa, Committee on Population 1993).

17 Chege and Askew (1997) cite this information from an unpublished report by J. Barasa and S. Kanani (1991), “An inventory study of community 
based distribution of family planning services," prepared for the National Council for Population and Development and UNFPA.

18 Personal communication from Inoussa Kabore about the Bazega Project in Burkina Faso (1998).

19 The CBD approach is particularly suited for diffusion of innovations because it uses community members rather than clinic personnel to introduce family planning. Diffusion works best when innovations are introduced to people by people who are similar to them (Rogers 1995).

20 The 1994 Zimbabwe DHS reported that 18 percent of women users of all modern methods were supplied by a ZNFPC CBD worker. (See Zimbabwe Central Statistical Office and Macro International 1995). In 1984, CBD was responsible for 43 percent of the couple-years of protection provided by the ZNFPC program (Boohene and Dow 1987).

21 See Frank and Bongaarts (1991) for discussion of the fertility transition in Africa. They postulate that fertility will remain the same in Africa in societies where contraceptives are used purely as replacements for postpartum abstinence.

22 School-based family planning promotion has been excluded from this analysis because it targets only one segment of the community. A comprehensive CBD program could include school-based activities, but on their own, school-based programs are not considered part of the CBD effort. Multiple youth-targeted integrated family planning and HIV/STD prevention programs do exist in Africa, however. Some examples are the Youth Reproductive Health Centre in Harar, Ethiopia (see International Planned Par- 
enthood Federation 1998) and the Central African Republic's Support to Youth for Responsible Sexuality program, which operates a condom social marketing program showing video tapes on condom use at motion picture houses in Bangui (see Supe and Blankhart 1996).

23 This approach is the fundamental strategy of the large public-sector programs in India and Pakistan: Promote family planning through campaigns, media events, and incentives, but maintain the locus of service delivery in clinics.

24 This approach was the basis of the success of CBD in East Asia and Latin America: Unmet need for family planning was extensive. Simple distribution of contraceptives had immediate and pronounced effects because the population was receptive to services.

25 In South Asia, micro-lending programs have proved to be a productive mechanism for developing women's autonomy and status. See Schuler et al. 1996 and Amin et al. 1998. Family planning programs benefit from micro-lending programs, because women's empowerment is significantly associated with contraceptive use, and credit-program members are more likely to be contraceptive users (Amin et al. 1996).

26 The Family Planning Association of Kenya (FPAK), for example, uses workplace motivators who function as CBD agents. They visit families in their homes at factory compounds, where they provide counseling, sell contraceptives, and refer clients to FPAK clinics for permanent contraceptive procedures (Johns Hopkins Population Communication Services 1997).

27 Deliberations concerning the demographic role of family planning programs have been facilitated by Easterlin's framework (see Easterlin 1975a 
and 1975b and Easterlin and Crimmins 1985). In this view, programs have an impact upon fertility by mitigating the costs of contraception that are defined broadly to include the social, psychological, monetary, and health constraints to contraceptive use. By reducing travel time and costs, CBD programs generate contraceptive use even if the demand for services is unchanged by services. A closely related effect of CBD concerns the role of psychologistic costs. The provision of family planning in convenient and familiar surroundings offsets the perception that clinics represent a "foreign" environment that is culturally alien and intimidating. Village services that provide outreach information, in combination with contraceptive services, can address concerns about privacy or social constraints to contraceptive use that would prevent couples from using a method. Programs, for example, can foster spousal communication about family planning. Family planning outreach can substitute for social support that would not otherwise arise. Mitigating the health costs of fertility regulation represents a further mechanism by means of which CBD programs can have effects. Disease resulting from minor ailments is extensive in rural settings, and prevalent ill health can greatly exaggerate the perceived health consequences of contraception. In the absence of information about methods, women often associate unrelated health problems with contraception and discontinue use when illness arises, even if the illness could not possibly relate to the practice of contraception. The "costs of contraception" thus represent the broad range of constraints to contraception among couples who would otherwise regulate their fertility. Mitigating such costs has been the central strategy of CBD programs. See, for example, Hermalin and Entwisle (1987) and Mauldin and Lapham (1987).

28 Figure 4 is modified from a diagram presented by Hermalin (1983) based on Easterlin's concept. See also Easterlin and Crimmins (1985). 
29 A useful review of how social, psychological, health, and monetary costs of contraception arise and how programs address these constraints appears in a review of the Easterlin framework by Hermalin (1983).

30 Demand can be altered by fostering the diffusion of new concepts of reproductive planning through communication and persuasion or simply by introducing services and technologies that were previously unknown (see Cleland 1985; Cleland and Wilson 1987). These pathways are not mutually exclusive; they can vary in importance according to their particular social or institutional settings. For three decades, seemingly endless and unproductive debate focused on the question of whether either of these sources of impact were demographically relevant concepts. Experiments and research demonstrated that programs could have an effect by showing that they can meet latent demand when they establish convenient contraceptive supply. Priorities shifted to questions concerning the relevance of family planning programs to settings where little or no latent demand exists. At present, greater consensus is found concerning the role of programs in settings with unmet need or latent demand than is found concerning the role of programs where demand for family planning is weak.

31 A 1994 study conducted in Mali showed that CBD and family planning education altered the fertility preferences of groups exposed to them. After exposure, each group reported wanting an average of two children fewer than they had wanted previously (Katz et al. 1998). See also Chowdhury et al. (1985) and Simmons et al. (1988). This view is not to be confused with Berelson's "beyond family planning" concept in which non-family planning strategies are proposed for situations where demand for family planning is weak (Berelson 1969). In the "beyond supply" perspective, CBD 
creates demand by introducing family planning and sustaining reproductive change through culturally sensitive approaches to service delivery (see Warwick 1988).

32 A series of studies in Asia has shown that seemingly formidable societal obstacles to family planning gradually dissipate with time, and that rigorous $\mathrm{CBD}$ can play a catalytic role that extends beyond simply supplying services. In Taiwan, for example, the practice of family planning increased and fertility declined before reproductive preferences changed (Chang et al. 1981). Also, in Indonesia, family planning adoption appears to have preceded other social changes (Freedman et al. 1980). Such findings suggest that programs foster the diffusion of reproductive innovation by introducing new behavior that subsequently changes norms and preferences. A program of family planning and health outreach in Bangladesh has been shown to influence women's roles and status (Simmons et al. 1992) and their reproductive aspirations (Simmons et al. 1988).

33 See reviews of this issue in Sinding et al. (1993) and Bongaarts and Phillips (1993).

34 The current demand for family planning in sub-Saharan Africa is not synonymous with the intention to limit fertility. Western contraceptive technology may be used by women in societies that value a two-year minimum birth interval who want to space their births rather than to limit them. Therefore, supplying these women with family planning services may leave birth intervals and total fertility largely unaltered (Bledsoe et al. 1994).

35 A 1998 international workshop on unmet need for contraception concluded that the opposition of the husband and health side effects (each real or 
feared) were the dominant reasons for unmet need (Casterline, personal communication). A 1997 review of the literature and empirical evidence on the causes of unmet need similarly concluded that fear of side effects and of husband's disapproval had significant effects on unmet need (Bhushan 1997). CBD has the potential to reduce both of these factors. See also Robey et al. (1996).

36 Pritchett (1994) theorizes that fertility is principally determined by the desire for children and that access or cost of family planning are not dominant factors. Van de Walle and Foster (1990) also attribute greater influence to cultural factors, and believe that little evidence exists to prove that inaccessibility is primarily responsible for the low level of method use. They remain advocates of family planning program expansion, however, stating that increased knowledge and availability of contraceptives in the present may serve women with spacing needs who may later choose to limit their fertility. The National Academy of Sciences, by contrast, has stated that "access to family planning is associated with contraceptive prevalence" (see National Research Council 1993).

37 If CBD results in increased demand for contraception before the costs of contraception are mitigated, CBD can lead to higher unmet need. This association has been illustrated in one experimental study in Ghana (Debpuur et al. 1998).

38 The Women's Studies Project of Family Health International studied the impact of family planning on women's lives in several countries, including Mali, Nigeria, and Zimbabwe (see Family Health International 1997). Projects included research in Mali to determine how the adoption of fam- 
ily planning influenced a woman's communication with her spouse and inlaws, her employment status, and her power in household decisionmaking. In Zimbabwe, an examination of the way contraceptive use has shaped academic and vocational goals of young women was conducted as well as a study about the consequences of family planning for women's quality of life, as they themselves define it.

39 The Navrongo Health Research Centre, in a remote area of northern Ghana, has monitored the adverse social consequences of family planning for women. The researchers have found that contraceptive use puts women at risk of physical abuse. Male desire for children is high, and contraception threatens male reproductive control (Bawah et al. 1998). Men are concerned that women won't live up to their obligation to bear children. Men also worry that contraception will free wives to have sex with other men. Women are concerned that their husband's disapproval of contraceptive use might lead them to withhold affection or take another wife. Use of contraceptives can also cause conflict with in-laws. For this reason, community health nurses report, women often prefer to obtain supplies directly from the community health center rather than at their homes. Such observations run counter to the geographic accessibility premise. Women prefer to obtain services away from home, in secrecy, rather than in their own homes. The lack of social support for contraceptive use results in secrecy and reduced reporting of use in Navrongo (Phillips et al. 1998).

40 Men may feel that they lose any decisionmaking power that is gained by women. Thus, "programs need to address strategic interests with an eye to minimizing opposition and gaining support from male leaders" (Drennan 1998:28). For example, programs could foster meetings among men to 
establish social legitimacy rather than targeting family members in isolation. In Navrongo, "to inform women mainly (or only) is not only seen as a public attempt to usurp a man's entitled power within his own home, but also puts women in the uncomfortable position of having to teach or persuade their husbands about family planning” (Biddlecom et al. 1997:21). In order to fulfill unmet need for family planning, social costs to women must be minimized by including men in program efforts and by reaching them through culturally appropriate channels (Population Council 1998).

41 See, for example, Caldwell and Caldwell 1987, 1988, 1990a, and 1990b; Lesthaeghe 1989; van de Walle and Foster 1990; Frank 1990; and van de Walle and Omideyi 1988. An influential paper by Caldwell and Caldwell (1988) argues that the conditions for demographic transition in Africa are fundamentally different from those in Asian settings. The circumstances of transition in East Africa have been complex, involving economic and social changes that set the stage for program success (see, for example, Mhloyi 1991).

42 Male heads of families, extended families, and kindred groups derive prestige from large families. Fertility early in marriage is nearly universal among young married women. Having borne numerous children confers status on older women. The social value of children is reinforced by pronatalist religious beliefs and social customs. A complete description of social influences on reproductive motives is beyond the scope of this report. See Caldwell and Caldwell (1987).

43 Microeconomic appraisals consistently show that the perceived benefits of having children far outweigh the direct costs to parents of rearing them. See Guyer (1981) for a discussion of economic security enhanced by childbearing. Wealth flows from children to parents, particularly because the 
costs of childbearing are sustained by extended families rather than by families of the nuclear household (see Caldwell 1976; Caldwell and Caldwell 1987). Child fostering tends to distribute the costs of childbearing (see, for example, Ainsworth 1993).

44 The structure of the African family and nature of marriage, particularly the custom of polygyny tends to weaken spousal communication and joint decisionmaking - factors that complicate efforts to introduce family planning. Dowry customs further diminish the reproductive autonomy of women, ensuring that the individual preferences of women are subordinated to the interests of family and kin. The economics of marriage underscore traditional beliefs in the importance of childbearing (National Research Council 1993).

45 A detailed review of this issue is beyond the scope of this brief report. For a comprehensive review of the literature, see Working Group on Factors Affecting Contraceptive Use (1993).

46 Some authors argue that the cultural basis for high fertility is eroding in Africa owing to changes in the economy, society, and climate of educational attainment for women. Urban populations in particular are becoming more receptive to the introduction of family planning services (see, for example, Kritz and Gurak 1989).

47 Some observers attribute the relatively rapid expansion of family planning programs in Botswana, Kenya, and Zimbabwe to the relatively favorable health conditions in those countries and their relatively low mortality rates among children (see National Research Council 1993).

48 See, for example, Wulf (1985) and Perrow (1970). In the organizational 
research literature, the application of social research in operations research is termed "strategic planning" (see World Bank 1993). A major field of organizational research and theory has developed in response to "opensystems theory" - perspectives on how to adapt organizational designs to their environment (see, for example, Katz and Kahn 1966). The "constrained demand" insight from social research represents an implicit invitation to embrace an open-systems perspective. This perspective is particularly relevant to $\mathrm{CBD}$, which, by definition, involves organizing services to suit the environment.

49 A useful example of this type of study is a recent exploration of community reactions to $\mathrm{CBD}$ in Ghana. After basic attitudes and beliefs were discussed, villagers were asked to comment on the program and suggest changes. Fundamental complaints emerged as well as practical suggestions on how the program could be improved. This study is discussed further below (Ministry of Health, Health Research Unit 1992). The twostage approach has also been used in Mali to design a CBD experiment. Issues in the design and implementation of service delivery were discussed in focus-group sessions. This approach implicitly responds to social constraints with appropriate strategies for CBD agent selection and motivation, supervisory system design, and communication and education activities (see Huntington et al. 1992). It is particularly useful in identifying the concerns of men, feasible CBD strategies for outreach to husbands, and means of fostering husband-wife communication (for example, see Turner 1991 and Makomva et al. 1991).

50 See Githiari (1986), Phillips et al. (1992), and Goldberg et al. (1989). For discussion of CBD and the fertility transition in Kenya, see Njogu (1991) and Cross et al. (1991). 
51 A 1995 study found that when CBD agents are known, people will use them as a supply source (Chege and Askew 1997). Although CBD agents are not the predominant source of family planning information for Kenyans, their supply role is more important in rural areas than in urban areas and among men who know of a CBD agent than among men who do not.

52 See Goldberg (1987 and 1989) for a discussion of programs in Chogoria, Kenya.

53 See Phillips et al. (1993). When the Kenyan Ministry of Health instituted a volunteer CBD program, supervisors and clinical staff were not oriented to perform the intense community organizational labor that was required to make the program work. Poor morale, weak accountability, high turnover, and other management problems arose because workers could not be held accountable for performance. Organizers of other volunteer CBD worker-compensation schemes argue convincingly that the reverse is true of their organizations: Because paying CBD workers would be inconsistent with their institutional style and mandate, paying would cause more problems than progress.

54 Market vendors who prosper from the scheme often sell large quantities of commodities to pharmacies or other retailers. Moreover market-trader sales may simply substitute for other commercial outlets for commodities rather than contribute to incremental contraceptive use.

55 Handing pilot projects over to public-sector agencies has been unsuccessful. Political support is often crucial to schemes, but lacking in practice. Where governors have been involved, for example, schemes have worked better than they have in settings where local government bureaucracies 
have taken part. Forming nongovernmental agencies (NGOs) in the model of traditional trader associations is a more promising strategy (Jinadu et al. 1993).

56 See the 1994 Zimbabwe Demographic and Health Survey (Zimbabwe Central Statistical Office and Macro International 1995). The TFR for women aged $15-49$ was 4.29 . The TFR was 4.22 for women aged $15-44$.

57 See Adamchak and Mbizvo (1990) for discussion of the effect of contraceptive prevalence on fertility in Zimbabwe.

58 See Bledsoe (1994), Dwyer and Hawa (1990), and Frank and Bongaarts (1991) for discussion of the use of contraceptives for spacing in Africa.

59 One careful study based on data from the Demographic and Health Survey has related areal data on the accessibility of services to individual respondent data on contraceptive use in Zimbabwe. No significant relationship emerged, bringing into question the hypothesis that CBD is responsible for reproductive change in that country (Wilkinson 1992). See Wilkinson (1991) for discussion of the relationship between contraceptive availability and use in other countries.

60 In a study of users who adopted in 1987, about one-third continued to receive supplies from CBD agents 12 months later (ZNFPC 1990).

61 A 1996 assessment of the Zimbabwe Family Planning Programme by Dube, Marangwanda, and Ndhlovu (1998) contained no information about the demographic role of CBD.

62 The Navrongo project is the first African experimental trial of the demo- 
graphic impact of family planning. A field trial of CBD program Type III is being implemented (Binka et al. 1995).

63 This finding illustrates a major methodological limitation of most CBD evaluation. Contraceptive users in Navrongo are known to deny use in survey interviews. The impact of the experiment on prevalence of use differs by cell, but this finding may be due to differential denial rather than differential use.

64 Syndromic management of village health workers is problematic for a number of reasons. First, asymptomatic cases are missed (Dadian 1996). Second, false-positive diagnoses occur frequently. A study in Giza, Egypt, cautioned against using the syndromic approach for diagnosis and treatment of reproductive tract infections. The study found that vaginal discharge was not a reliable predictor of reproductive tract infections. Furthermore, women's perceptions of the abnormality of their discharges were not useful; many perceived as normal discharges that were medically suspect (Zurayk et al. 1995).

65 Some Kenyan CBD agencies use Type II models with unpaid workers. This approach has not worked well. It requires an unpaid worker to be an active canvasser of communities. Uncompensated workers refuse to or cannot sustain the necessary level of effort to make CBD work.

66 In Tanzania, for example, a project has experimented with forming village health committees that charge a fee of one dollar per year to families for health insurance. The revenue is used to support outreach that includes family planning (Neuvians 1989).

67 The UNICEF-sponsored Bamako Initiative distributes essential drugs to 
members of village committees who are trained to provide primary-healthcare services. Service fees are paid into village revolving funds that finance outreach salaries. Plans of the Ministry of Health call for adding CBD to the scheme (Agyepong and Marfo 1992).

68 Although CBD research is often justified as investigation guided by hypotheses, results almost always confirm substantive hypotheses. Null results of high-risk trials could be more useful than confirmatory low-risk studies. One such CBD experiment in Rwanda used volunteer community development workers to distribute oral contraceptives in a rural area. Results were compared with those from a service area where workers were trained to provide outreach information, education, and communication activities, but were not equipped with CBD commodities. A third area offered clinical services only. Contraceptive prevalence increased in all areas over the two-year project period. In comparison areas, prevalence increased from 7 to 10 percent. The overall change in CBD areas was greater, but only because baseline prevalence was low: 2 percent to 11 percent. The difference between 11 percent and 10 percent is statistically significant, but too small to provide a resounding endorsement of CBD. The main impact was in the information, education, and communication cell with no $\mathrm{CBD}$, where prevalence increased from 5 to 36 percent. This seemingly counterintuitive result is explained by the active local political support for family planning in the information area, and the apparent lack of support in CBD areas. The finding is not thoroughly explained, however, and the policy implications of the Rwanda results are unclear. Evidence appears to suggest that successful implementation of CBD operations does not assure impact. Local political and administrative support for CBD can be crucial to program success. When such support is lacking, CBD can fail owing to implementation lapses, lack of publicity, or other operational problems. 
69 A large-scale health-development program in Tanzania illustrates this approach. The Tanzania Essential Health Services Project (TEHIP) tests the hypothesis that health status can be improved through decentralization and resource mobilization. A process for organizational change and policy development is specified in the design, but operational mechanisms to be used are developed by field teams. This flexible approach to strategic planning might be useful in developing $\mathrm{CBD}$ designs that require organizational change in host agencies (see also Simmons et al. 1997 and Brieger et al. 1988).

70 The market-vendor approach taken in Nigeria is a good idea that should be included as a component of a more general community health and family planning outreach effort. See Jinadu et al. (1993).

71 In the Gambia, an interesting study was conducted concerning how to involve religious leaders in family planning; in Ghana a useful study of TBAs is under way; in Nigeria, market traders have been used to sell family planning commodities; in Tanzania, community financing has supported primary-health-care outreach. Twaha et al. (1989) review lessons from projects on community-managed health care in Tanzania. These lessons are potentially relevant to family planning as well. In Rombo District of the Kilamanjaro region, a project has demonstrated a scheme for soliciting household payments for health insurance cards. The funds generated are paid into a revolving account used to finance workers' stipends for family planning CBD activities and other primary-health-care outreach (Neuvians 1989). In Kenya, village volunteers have provided family planning through women's associations. Although such ideas are interesting program components, such strategies should be configured in one place as a unified system of care. An untested hypothesis is that all of these elements taken 
together would succeed in even the most constrained setting. This hypothesis is guiding the Navrongo and Bazega experiments.

72 The organizational structure of African social institutions is believed to explain diverse African responses to innovation and political modernization. See Apter (1966) for discussion of the compatibility of traditional social structure with modern political structure as it leads to success or failure in the political modernization of Ghana and Uganda.

73 Bawah et al. (1998) highlight the strains placed on gender relations that result from contraceptive use among the Kassena-Nankana in northern Ghana.

74 The complexity of African cultural history is discussed in Freund (1984), Jefferson (1978), and Roland (1991).

75 The shift in human settlement patterns in Africa is extreme. By the year 2000,38 percent of the African population will be urban, and by 2030, that figure will increase to 54 percent (United Nations 1998). In sub-Saharan Africa, living conditions remain favorable for big-city residents. However, "mega villages" of between 50 thousand and one million people suffer infant mortality rates that exceed those for both smaller and larger cities (Brockerhoff and Brennan 1998). Brockerhoff and Brennan conclude that the poor health conditions in these mega villages are correlated with high growth rates and may be improved by continued efforts to facilitate fertility reduction.

76 An example of this type of work is the "participatory learning approach" used to develop the Bazega experiment in Burkina Faso (Kabore 1998). See also Nazzar et al. (1995). 
77 The term "theory" has acquired a nearly topical taboo status in the CBD literature, connoting academic rather than practical research pursuits. In the commercial operations research industry, however, theoretical perspectives are more generally applied than in the family planning field. Systematic review of commercial organizational research literature would be instructive in this regard. Analyses of organizations, for example, often begin with appraisals of the strategic fit of organizations to environmental conditions, with mismatched organization-environment interfaces signaling directions for necessary change and restructuring (see, for example, Lawrence and Lorsch 1969).

78 Organizational development uses techniques of diagnosis, intervention, planned change, and rediagnosis to study the process of introducing operational improvements in troubled organizations. The compendium edited by Glaser et al. (1983) is useful in this area. Panels of administrators are convened to commission research, weigh results, and monitor change. Organizational development approaches use operations research as a mechanism in the process of introducing change rather than as an end product of research (see, for example, French and Bell 1978). Situation analysis has been a productive tool for examining the climate of care in programs, including programs that have failed to achieve their full potential. Situation analysis may have productive applications in $\mathrm{CBD}$ evaluation when used as a tool in CBD organizational development.

79 There are, nonetheless, settings in Africa where research on second-generation CBD issues is greatly needed. For example, operations research is needed on the issue of payment of workers, charges to clients, and costrecovery schemes in such settings as Zimbabwe and Kenya, where family planning is known to be successful, but where budget constraints prevent 
service expansion. (See Mundy and Askew 1994, Lewis et al. 1992, and Dube et al. 1998). Whether couples will pay for services is a more relevant issue after a program has been legitimized in society and its services are in demand (see Cleland et al. 1994). However, encumbering African programs with too many concerns about developing sustainable strategies risks making the CBD effort face too many constraints so that opportunities for self-sustained demographic transitions are lost as a consequence.

80 Interest has been renewed in the practical aspects of the relative impact of alternative strategies, rather than about the demographic impact of family planning programs per se (see Freedman and Freedman 1992 and Simmons 1992).

\section{References}

Aboderin, M.A. 1987. "An overview of a community-based distribution project in Oyo State of Nigeria." In Proceedings: A Conference on CommunityBased Distribution and Alternative Delivery Systems in Africa: Harare, Zimbabwe, 3-7 November, 1986. Washington, DC: American Public Health Association.

Adamchak, Donald J. and Michael T. Mbizvo. 1990. "The relationship between fertility and contraceptive prevalence in Zimbabwe." International Family Planning Perspectives 16(3): 103-111.

Adepoju, Aderanti and Wariora Mbugua. 1996. "The African family: An overview of changing forms." In Family, Population and Development in Africa, ed. Aderanti Adepoju. London: Zed Books. Pp. 41-59.

Africa Operations Research and Technical Assistance Project II. 1998. "Community Based Distribution of Information and Services." Programme Briefs. The Population Council. 
African Medical and Research Foundation (AMREF) and The Population Council. 1993. Expanding Family Planning Delivery Systems Using Traditional Health Practitioners: An Operations Research Study in Rural Kenya. Nairobi: AMREF and The Population Council.

Agyepong, Irene and Constance Marfo. 1992. "Is there a place for community health worker programmes in primary health care delivery in Ghana?" Unpublished report of the Internal Evaluation of the Dangbe West District Community Health Workers Programme. Accra: District Health Management Team, Ministry of Health.

Ainsworth, Martha 1993. "Economic Aspects of Child Fostering in Cote d'Ivoire." LSMS Working Paper No. 92. Washington, DC: The World Bank.

Akuetteh, L.S.N. 1987. "The Ghana social marketing programme (GSMP).” In Proceedings: A Conference on Community-Based Distribution and Alternative Delivery Systems in Africa: Harare, Zimbabwe, 3-7 November, 1986. Washington, DC: American Public Health Association.

Amin, Ruhul, Yiping Li, and Ashrad Ahmed. 1996. "Women's credit programs and family planning in rural Bangladesh." International Family Planning Perspectives 22(4): 158-162.

Amin, Ruhul, Stanley Becker, and A. Bayes. 1998. "NGO-promoted microcredit programs and women's empowerment in rural Bangladesh: Quantitative and qualitative evidence." Journal of Developing Areas 32(2): 221-236.

Ampofo, Daniel A., David D. Nichols, Samual Ofosu-Amaah, Stewart Blumenfeld, and Alfred K. Neumann. 1976. "The Danfa Family Planning Program in rural Ghana.” Studies in Family Planning 7(10): 266-274.

Anonymous. 1976. The Indonesia Family Planning Program: Basic Strategies. Jakarta, Indonesia: National Family Planning Coordinating Board $(\mathrm{BKKBN})$.

1994. "Partners in family planning." African Alternatives (7-8): 3-4. 
1995. "Male CBD agents effective at reaching men with family planning messages." African Alternatives 2(1): 6-7.

. 1996a. "CBDs take messages to communities in Tanzania." JOICFP News (260): 2.

1996b. “Tanzanian project expands.” JOICFP News (267): 5.

1997. “Zambian project serving as African model.” JOICFP News (280): 7.

Apter, David. 1966. "The role of traditionalism in the political modernization of Ghana and Uganda." In Political Development and Social Change. New York: John Wiley and Sons.

Aryee, Andrew F. 1989. "Socio-cultural policies and programmes for efficient family planning in Africa." In Developments in Family Planning Policies and Programmes in Africa. Legon, Ghana: University of Ghana, Regional Institute for Population Studies.

Askew, Ian and Atigur R. Khan. 1990. "Community participation in national family planning programs: Some organizational issues.” Studies in Family Planning 21(3): 127-142.

Association Burkinabe des Sages-Femmes and The Population Council. 1993. "An operations research (OR) study to test a family planning motivation and referral program using satisfied contraceptive acceptors and midwives." In Operations Research Family Planning Database Project Summaries. New York: The Population Council.

Atkinson, Linda, Robert Castadot, Allan Cuadros, and Allan G. Rosenfield. 1974. "Oral contraceptives: Consideration of safety in nonclinical distribution." Studies in Family Planning 5(8): 242-249.

Awasum, D.N. 1992. Progress Report Number Two: Project No. C191.17A/ C]92.10A of the Male Opinion Leaders in the Promotion of Family Planning in Nkambe Donga Mantung. The Population Council Operations Research and Technical Assistance Project documentation. 
Bakouan, Didier, Pascaline Sebgo, Ian Askew, Youssouf Ouedraogo, Placide Tapsoba, and Claire Viadro. 1992. Situation Analysis of the Family Planning Program in Burkina Faso. Final report (condensed). New York: The Population Council, Africa Operations Research and Technical Assistance Project.

Bankole, Akinrinola. 1995. "Desired fertility and fertility behavior among the Yoruba of Nigeria: A study of couple preferences and subsequent fertility." Population Studies 49: 317-328.

Barry, T. 1996. "Quality of care: From concept to action: A way ahead for subSaharan Africa FP\&RH programmes." African Journal of Fertility, Sexuality and Reproductive Health 1(2): 85-91.

Bawah, Ayaga Agula, Patricia Akweongo, Ruth Simmons, and James F. Phillips. 1999. "Women's fears and men's anxieties: The impact of family planning on gender relations in northern Ghana." Studies in Family Planning 30(1): $54-66$.

Beckhard, Richard. 1969. Organizational Development: Strategies and Models. Reading, MA: Addison-Wesley Publishing Company.

Bennis, Warren. 1969. Organizational Development: Its Nature, Origins, and Prospects. Reading, MA: Addison-Wesley Publishing Company.

Berelson, Bernard. 1969. "Beyond family planning." Studies in Family Planning 1(38): 1-16.

Bernhart, Michael H. 1991. "Management of family planning programs and operations research." In Operations Research: Helping Family Planning Programs Work Better, ed. Myrna Seidman and Marjorie C. Horn. New York: Wiley-Liss.

Bertrand, Jane T. 1991. "Recent lessons from operations research on service delivery mechanisms." In Operations Research: Helping Family Planning Programs Work Better, ed. Myrna Seidman and Marjorie C. Horn. New York: Wiley-Liss. 
Bertrand, Jane T., Nlandu Mangani, and Matondo Mansilu. 1984. "The acceptability of household distribution of contraceptives in Zaire." International Family Planning Perspectives 10(1): 21-26.

Bertrand, Jane T., Nlandu Mangani, Matondo Mansilu, Mark E. McBride, and Jeffrey L. Tharp. 1986. "Strategies for the delivery of family planning services in Bas Zaire." International Family Planning Perspectives 12(4): $108-115$.

Bertrand, Jane T., Mark E. McBride, Nlandu Mangani, Nancy C. Baughman, and Mombela Kinuani. 1993. "Community-based distribution of contraceptives in Zaire.” International Family Planning Perspectives 19(3): 84-91.

Bhushan, Indu. 1997. "Understanding Unmet Need." Working Paper No. 4. Baltimore: The Johns Hopkins School of Public Health Center for Communication Programs.

Biddlecom, Ann E., Eva Tagoe-Darko, and Kubaje Adazu. 1997. "Factors underlying unmet need for family planning in Kassena-Nankana District, Ghana." Unpublished.

Biddlecom, Ann E. and Bolaji M. Fapohunda. 1998. Covert contraceptive use: Prevalence, motivations, and consequences." Studies in Family Planning 29(4): 360-372.

Binka, Fred N., Alex Nazzar, and James F. Phillips. 1995. “The Navrongo Community Health and Family Planning Project." Studies in Family Planning 26(3): 121-139.

Bledsoe, Caroline H., Allen G. Hill, Umberto D'Alessandro, and Patricia Langerock. 1994. "Constructing natural fertility: The use of Western contraceptive technologies in rural Gambia." Population and Development Review 20(1): 81-113.

Bledsoe, Caroline H., Fatoumatta Banja, and Allan G. Hill. 1998. "Reproductive mishaps and Western contraception: African challenges to Western fertility theory." Population and Development Review 24(1): 15-57. 
Bongaarts, John and James F. Phillips. 1993. "The demand for family planning and implications for supply strategies in sub-Saharan Africa." Paper prepared for the Africa Technical Department, World Bank.

Bongaarts, John and Judith Bruce. 1995. "The causes of unmet need for contraception and the social content of services." Studies in Family Planning 26(2): 57-75.

Boohene, Esther and Thomas Dow, Jr. 1987. "Contraceptive prevalence and family planning program effort in Zimbabwe." International Family Planning Perspectives 13(1): 1-7.

Brieger, W., J. Ramakrishna, S. Akpovi, and J. Adeniyi. 1988. “Organizational development as a health education strategy to maintain community involvement in PHC management." International Quarterly of Community Health Education 8(4): 351-374.

Brockerhoff, Martin and Ellen Brennan. 1998. "The poverty of cities in developing regions." Population and Development Review 24(1): 75-114.

Caldwell, John C. 1976. The Socio-economic Explanation of High Fertility. Canberra: The Australian National University.

Caldwell, John C. and Pat Caldwell. 1987. "The cultural context of high fertility in sub-Saharan Africa." Population and Development Review 13(3): 409437.

— 1988. "Is the Asian family planning program model suited to Africa?" Studies in Family Planning 19(1): 19-28.

_. 1990a. "High fertility in sub-Saharan Africa." Scientific American May 1990: 118-125.

- 1990b. "Cultural forces tending to sustain high fertility." In Population Growth and Reproduction in Sub-Saharan Africa, ed. George T.F. Acsadi, Gwendolyn Johnson-Acsadi, and Rodolfo A. Bulatao. Washington, DC: The World Bank. 
Cameroon Ministry of Public Health and The Population Council. 1993. "Promotion and delivery of family planning in the Donga-Mantung: An operations research (OR) study on the role of male opinion leaders." In Operations Research Family Planning Database Project Summaries. New York: The Population Council.

Casterline, John 1998. Personal communication, from a conference entitled "Unmet Need for Family Planning in Comparative Perspective: An International Workshop." Nairobi, 23-25 June.

Center for African Family Studies. 1995a. "Findings from the Sub-Saharan Africa Urban Family Planning Study, Bulawayo City Report.” Arlington, VA: John Snow International Family Planning Service Expansion and Technical Support (SEATS).

1995b. "Findings from the Sub-Saharan Africa Urban Family Planning Study, Mombasa City Report.” Arlington, VA: John Snow International Family Planning Service Expansion and Technical Support.

_. 1995c. "Findings from the Sub-Saharan Africa Urban Family Planning Study, Blantyre City Report.” Arlington, VA: John Snow International Family Planning Service Expansion and Technical Support.

Center for Population and Family Health. 1989. Operations Research Program, Five-Year Report. Unpublished report to USAID, DPE-3030-A-00-4094.

Chang, Ming-Cheng., Ronald Freedman, and Te-Hsiung Sun. 1981. "Trends in fertility, family size preferences and family planning practice: Taiwan, 1961-80." Studies in Family Planning 12(5): 211-228.

Chege, Jane Njeri and Ian Askew. 1997. "An Assessment of Community-Based Family Planning Programmes in Kenya.” Africa Operations Research and Technical Assistance Project II. Nairobi: The Population Council.

Chege, Jane Njeri, Naomi Rutenberg, Barbara Janowitz, and Andy Thompson. 1998. Factors Affecting the Outputs and Costs of Community-based Distribution of Family Planning Services in Tanzania. New York: The Popu- 
lation Council Africa Operations Research and Technical Assistance Project II and Research Triangle Park, NC: Family Health International.

Chowdhury, A.I., James F. Phillips, and Makhlisur Rahman. 1985. "Predicting the adoption of contraception: A multivariate analysis of contraceptive intention and subsequent use in Matlab Thana, Bangladesh." In Principles and Practice of Statistic in Medicine, ed. R.N. Srivastava, B.L. Verma, and G.D. Shukla. Bombay: Himalaya Publishing House.

Cleland, John 1985. "Marital fertility decline in developing countries: Theory and the evidence." In Reproductive Change in Developing Countries: Insights from the World Fertility Survey, ed. John Cleland and John Hobcraft. Oxford: Oxford University Press. Pp. 223-252.

Cleland, John and Christopher Wilson. 1987. "Demand theories of the fertility transition: An iconoclastic view." Population Studies 41(1): 5-30.

Cleland, John, James F. Phillips, Sajeda Amin, and Golam M. Kamal. 1994. The Determinants of Reproductive Change in Bangladesh. Washington, DC: The World Bank.

Cross, Anne R., Walter Obungu, and Paul Kizito. 1991. "Evidence of a transition to lower fertility in Kenya." International Family Planning Perspectives 17(1): 4-7.

D'Cruz-Grote, Doris. 1997. Prevention of Sexual Transmission of HIV/STD in Developing Countries: Experiences and Concepts. Eschborn, Germany: Deutsche Gesellschaft für Technische Zusammenarbeit (GTZ) .

Dadian, Margaret J. 1996. "Syndromic management: Promoting effective STD diagnosis in resource-poor settings." AIDScaptions 3(1): 9-13.

- 1997. "Condom sales boom as Rwanda and Haiti struggle to rebuild." AIDScaptions 4(1): 4-8.

Debpuur, Cornelius, Alex Nazzar, James F. Phillips, Pierre Ngom, and Fred N. Binka. 1998. "The Navrongo Community Health and Family Planning 
Project: Preliminary impact of project activities on reproductive behavior." Paper prepared for the IUSSP Seminar on Reproductive Change in Sub-Saharan Africa, Nairobi, 2-4 November.

Delano, Grace B. 1987. "Organizing for community participation in a rural health care/family planning project: The Oyo State, Nigeria experience." In Proceedings: A Conference on Community-Based Distribution and Alternative Delivery Systems in Africa: Harare, Zimbabwe, 3-7 November, 1986. Washington, DC: American Public Health Association.

— 1990. "Community based family planning in Africa." Populi 17(2): 5455.

Department of Community Medicine, Faculty of Medicine, University of Khartoum, and Operations Research Program, Center for Population and Family Health, Columbia University. 1988. "The Sudan community based family health project: Final report, March 31, 1988." New York: Operations Research Program, Center for Population and Family Health.

Division of Family Health, Ministry of Health, National Council for Population and Development, and The Population Council. 1991. CBD Policy Guidelines Workshop: Silver Springs Hotel, Nairobi, 12-15 August, 1990. (Updated May 1991).

Doucoure, Arkia, Diane Djeneba, Fanta Toure, Amadou Traore, Seydou Doumbia, Diouratie Sanogo, Dale Huntington, and Claire Viadro. 1998. "The effect of a family planning CBD project in Mali." In Family Planning Operations Research: A Book of Readings, ed. James R. Foreit and Tomas Frejka. New York: Population Council.

Douglas, A. 1997. “A visit to the Sudan.” FPIA News (1): 3, 7.

Drennan, Megan. 1998. "New perspectives on men's participation.” Population Reports Series J, Number 46.

Dube, Hazel M.B., Caroline S. Marangwanda, and Lewis Ndhlovu. 1998. "An Assessment of the Zimbabwe Family Planning Programme: Results from 
the 1996 Situation Analysis Study." Harare: Zimbabwe National Family Planning Council and Nairobi: Africa Operations Research and Technical Assistance Project II, The Population Council.

Dwyer, Joseph C. and Jeanne M. Haws. 1990. "Is permanent contraception acceptable in sub-Saharan Africa?" Studies in Family Planning 21(6): 322326.

Easterlin, Richard A. 1975a. "An economic framework for fertility analysis." Studies in Family Planning 6(3): 54-63.

- 1975b. "The economics and sociology of fertility: A synthesis." In Historical Studies of Changing Fertility, ed. Charles Tilly. Princeton: Princeton University Press.

Easterlin, Richard A. and Eileen M. Crimmins. 1985. The Fertility Revolution: A Supply-Demand Analysis. Chicago: The University of Chicago Press.

Ebo, A. 1987. "The medical rationale for CBD strategies." In Proceedings: A Conference on Community-Based Distribution and Alternative Delivery Systems in Africa: Harare, Zimbabwe, 3-7 November, 1986. Washington, DC: American Public Health Association.

El Tom, Abdul Rahman. 1985. "The Sudan community-based health and family planning project: Description of a training course." In Health and Family Planning in Community-Based Distribution Programs, ed. Maria Wawer, Sandra Huffman, Deborah Cebula, and Richard Osborn. Boulder, CO: Westview Press. Pp. 417-422.

El Tom, Abdul Rahman, Nadia Mubarak, Suzanne Wesley, M. Hytham Matthew, and Donald Lauro. 1984. "Developing the skills of illiterate health workers." World Health Forum 5(3): 216-220.

El Tom, Abdul Rahman, M. Hytham Matthew, Suzanne Wesley, and Donald Lauro. 1984-85. "Introducing integrated health services in a traditional society: The Sudan community-based family health project." International Quarterly of Community Health Education 5(3): 187-202. 
El Tom, Abdul Rahman, Abdul Aziz Farah, Donald Lauro, and Thomas Fenn. 1987. "Community and individual acceptance: Family planning services in the Sudan." The Ahfad Journal 4(1): 12-30.

El Tom, Abdul Rahman, Donald Lauro, Abdel Aziz Farah, Regina McNamara, and E.F. Ali Ahmed. 1989. "Family planning in the Sudan: A pilot project success story." World Health Forum 10(3/4): 333-343.

Family Health International (FHI). 1997. "The impact of family planning and reproductive health on women's lives: A conceptual framework." Research Triangle Park, NC: FHI, Women's Studies Project.

FHI and AIDS Control and Prevention Project. 1994. AIDSCAP Quarterly Country Progress Report, 2nd Quarter, FY 94. Research Triangle Park, NC: FHI.

Family Planning Association of Kenya (FPAK) and the Africa Operations Research and Technical Assistance Project. 1995. "Increasing male involvement in the Family Planning Association of Kenya (FPAK) family planning program." Unpublished.

Farooq, Gazi M. and Lawrence A. Adeokun. 1976. "Impact of a rural family planning program in Ishan, Nigeria, 1969-72." Studies in Family Planning 7(6): 158-169.

Ferguson, Allan 1998. "Large-scale community-based distribution in Kenya: The right place at the right time?" Unpublished.

Fertility Research Unit. 1985. "Ibadan market women project: An innovative approach to family planning services in urban Nigeria." Ibadan, Nigeria: University of Ibadan University College Hospital, Department of Obstetrics and Gynaecology. Unpublished.

Foord, Frances. 1995. "Strengthening referral systems." In Issues in Essential Obstetric Care, Report of a Technical Meeting of the Inter-Agency Group for Safe Motherhood, 1995, ed. Diana M. Measham and Virginia D. Kallianes. New York: The Population Council. 
Foreit, James R. and Karen Foreit. 1984. "Quarterly versus monthly supervision of CBD family planning programs: An experimental program in northeast Brazil." Studies in Family Planning 15(3): 112-120.

Foreit, James R., Martin E. Gorosh, Duff G. Gillespie, and C. Gary Merritt. 1978. "Community-based and commercial contraceptive distribution: An inventory and appraisal." Population Reports Series J, Number 19.

Foreit, James R., Federico R. León, and Carlos Eduardo Aramburo. 1991. "La Calidad de Atención en los Programas Latinoamericanos de Distribución Comunitária: Estrategias de Evaluación y Mejoramiento.” Population Council Regional Working Paper No. 25. Querotaro, Mexico: The Population Council.

Frank, Odile. 1990. "The demand for fertility control." In Population Growth and Reproduction in Sub-Saharan Africa: Technical Analyses of Fertility and Its Consequences, A World Bank Symposium, ed. George T.F. Acsadi, Gwendolyn Johnson-Acsadi, and Rodolfo A. Bulatao. Washington, DC: The World Bank. Pp. 186-198.

Frank, Odile and John Bongaarts. 1991. "Behavioural and biological determinants of fertility transition in sub-Saharan Africa." Statistics in Medicine 10(2): 161-175.

Freedman, Ronald. 1987. "The contribution of social science to population policy and family planning program effectiveness." Studies in Family Planning 18(2): 57-82.

Freedman, Ronald and Ann K. Blanc. 1991. "Fertility transition: An update." Paper presented at the Demographic and Health Surveys World Conference, 5-7 August, Washington, DC. Unpublished.

Freedman, Ronald and Deborah Freedman. 1992. "The role of family planning programmes as a fertility determinant." In Family Planning Programmes and Fertility, ed. James F. Phillips and John. A. Ross. Oxford: Clarendon Press. 
Freedman, Ronald, Siew Ean Khoo, and Bondun Supraptilah. 1980. "Modern contraceptive use in Indonesia: A challenge to conventional wisdom." International Family Planning Perspectives 7(1): 3-15.

French, William L. and C.H. Bell. 1978. Organization and Development: Behavioral Science Interventions for Organizational Change. Englewood Cliffs, NJ: Prentice Hall.

Freund, Bill. 1984. The Making of Contemporary Africa: The Development of African Society Since 1800. Bloomington: Indiana University Press.

Futures Group International. 1995. "SOMARC launches five new condom campaigns." SOMARC Highlights (3): 3-4.

Gallen, Moira and Ward Rinehart. 1986. "Operations Research: Lessons for Policy and Programs.” Population Reports Series J, Number 31.

Ghana Registered Midwives Association and Center for Population and Family Health. 1990. "Final Report-Operations Research Project, Ghana Registered Midwives Association Family Planning Program.” New York: Center for Population and Family Health, Columbia University.

Glaser, Edward M., Harold H. Abelson, and Kathalee N. Garrison. 1983. Putting Knowledge to Use. San Francisco: Jossey-Bass Publishers.

Goldberg, Howard I., Alison Spitz, Malcolm McNeil, Abigail Krystall, and Kees de Boer. 1987. "1985 Chogoria Community Health Survey: Report of principal findings.” Chogoria, Kenya: Community Health Department, P.C.E.A. Chogoria Hospital.

Goldberg, Howard I., I. Malcolm McNeil, and Alison Spitz. 1989. "Contraceptive use and fertility decline in Chogoria, Kenya." Studies in Family Planning 20(1): 17-25.

Gray, Ronald H. and Miriam H. Labbok. 1985. "Family planning components in community-based distribution projects: Risk/benefit consideration in the choice of methods." In Health and Family Planning in Community-Based 
Distribution Programs, ed. Maria Wawer, Sandra Huffman, Deborah Cebula, and Richard Osborn. Boulder, CO: Westview Press. Pp. 65-104.

Guilkey, David K. and Susan H. Cochrane. 1992. "Zimbabwe: Determinants of contraceptive use at the leading edge of fertility transition in sub-Saharan Africa." Unpublished.

Guyer, Jane. 1981. "Household and community in African studies." African Studies Review 24(2-3): 87-137.

Hammerslough, Charles R. 1991. "Women's groups and fertility transition in Kenya." Unpublished.

. 1992. "Proximity to contraceptive services and fertility transition in rural Kenya.” International Family Planning Perspectives 18(2): 54-58.

Haryono, Suyono and Thomas H. Reese. 1978. "Integrating Village Family Planning and Primary Health Services: The Indonesia Perspective." Technical Report Series No. 18 (January). Jakarta: National Family Planning Coordinating Board.

Hauser, Philip M. 1962. "On designs for experiments and research in fertility control.” In Research in Family Planning, ed. Clyde V. Kiser. Princeton: Princeton University Press. Pp. 463-474.

Hermalin, Albert I. 1975. "Regression analysis of areal data." In Measuring the Effect of Family Planning Programs on Fertility, ed. C. Chandrasekaran and Albert I. Hermalin. Liège: Ordina Editions.

. 1983. "Fertility regulation and its costs: A critical essay." In Determinants of Fertility in Developing Countries, ed. Rodolfo A. Bulatao and Ronald D. Lee. New York: Academic Press.

Hermalin, Albert I. and Barbara Entwisle. 1987. "The availability and accessibility of contraceptive services." In Organizing for Effective Family Planning Programs, ed. Robert J. Lapham and George B. Simmons. Washington, DC: National Academy Press. 
Horn, Marjorie C., Nancy Pendarvis Harris, Susan Kren, and Marc A. Okunnu. 1992. "Private sector assessment, Family Health Services Project." Report to the United States Agency for International Development. Unpublished.

Huber, Douglas H. and Sallie Craig Huber. 1975. "Screening oral contraceptive candidates and inconsequential pelvic examinations." Studies in Family Planning 6(2): 49-51.

Huber, Sallie Craig, Phyllis T. Piotrow, Malcolm Potts, B. Chir, Stephen L. Isaacs, and Reimert T. Ravenholt. 1975. "Contraceptive Distribution: Taking Supplies to Villages and Households." Population Reports Series J, Number 5.

Huntington, Dale, D. Sanogo, S. Doumbia, C. Viadro, and S. Bocoum. 1992. "Using operations research to implement a family planning community based distribution project in rural Mali." Paper prepared for the International Council of International Health Conference, 15-17 June, Crystal City, VA.

International Planned Parenthood Federation (IPPF). 1996. "Community-based services in Africa: The Ouagadougou workshop.” London: IPPF.

—. 1998. “African Region Report.” In Annual Review 1997-1998. www.ippf.org/ review/africa.htm.

Isaacs, Stephen L. 1975. "Non-physician distribution of contraception in Latin America and the Caribbean." Family Planning Perspectives 7(4): 158-164.

Iyun, B. Folasade. 1985. "Ibadan market documentation study." Report to the Ibadan Market-Based Health and Family Planning Project. Unpublished.

_. 1988. "Up-dating the Ibadan market documentation study: Market stalls and agents." Report to the Ibadan Market-Based Health and Family Planning Project. Unpublished.

Iyun, B. Folasade, E. Adewale Oke, and O. Olusegun Matanmi. 1987. “Analysis of a baseline survey for the Ibadan low cost market based health care de- 
livery project." Report to the Fertility Research Unit, College of Medicine, University of Ibadan and the Center for Population and Family Health, Columbia University, New York. Unpublished.

Jain, Anrudh, Judith Bruce, and Sushil Kumar. 1992. "Quality of services, programme efforts, and fertility reduction." In Family Planning Programmes and Fertility, ed. James F. Phillips and John A. Ross. Oxford: Clarendon Press. Pp. 202-221.

Jinadu, Musa K., James F. Phillips, and Thomas T. Kane. 1993. "Market vendor distribution of contraceptives in Nigeria: A synthesis of experience and achievements." Report prepared for the Africa Operations Research and Technical Assistance Project, The Population Council. Unpublished.

Johns Hopkins Population Communication Services. 1997. "Reaching Men Worldwide: Lessons Learned from Family Planning and Communication Projects, 1986-1996.” Working Paper Series No.3. Baltimore: Johns Hopkins School of Public Health, Center for Communication Programs.

Kabore, Inoussa. 1998. Social Scientist, The Population Council, Ouagadougou. Personal communication to James F. Phillips.

Kanani, Salvatore and John Barasa. 1992. "An inventory study of community-based distribution of family planning." Report to the National Council for Population and Development and to United Nations Population Fund. Unpublished.

Kaseje, Dan C.O. and Harrison C. Spencer. 1987. "The Saradidi, Kenya Rural Health Development Programme." Annals of Tropical Medicine and Parasitology 81, supplement 1:1-12.

Katz, Donald and Robert Kahn. 1966. The Social Psychology of Organizations. New York: John Wiley and Sons.

Katz, Karen R., Caroline G. West, Fode Doumbia, and Fatoumata Kane. 1998. "Increasing access to family planning services in rural Mali through community-based distribution." International Family Planning Perspectives 24(3): 104-110. 
Kennedy, Barbara 1987. "Bringing family planning to the people of sub-Saharan Africa." In Proceedings: A Conference on Community-Based Distribution and Alternative Delivery Systems in Africa: Harare, Zimbabwe, 3-7 November, 1986. Washington, DC: American Public Health Association.

Keyonzo, Nelson A. 1982. "An evaluation of Maendeleyo ya Wanawake Organization: Maternal and child health and family planning motivation in Kenya." report (May). Nairobi: Maendeleyo. Unpublished.

- 1984. "A review of three community-based distribution of contraceptives programmes in rural Kenya.” Boston: Pathfinder Fund Project Reports. Unpublished.

Keyonzo, Nelson A., John Kekovole, and Gary L. Lewis. 1989a. “An evaluation of the Family Planning Association of Kenya Community Based Distribution Pilot Project, Volume 1: Major findings and selected recommendations." Nairobi: Centre for African Family Studies. Unpublished.

Kinzoni, Minuku and Nlandu Mangani. 1987. "The CBD programme of family planning services of Zaire (PRODEF).” In Proceedings: A Conference on Community-Based Distribution and Alternative Delivery Systems in Africa: Harare, Zimbabwe, 3-7 November, 1986. Washington, DC: American Public Health Association.

Koblinsky, Marjorie A., Susan J.G. Brechin, Samuel Clark, Mian Bazle Hossain, Chandan Saha, and Yousof Hasan. 1986. "Daily and Monthly Work Routines of the Government Family Planning Worker: The Family Welfare Assistant (FWA).” Operation Paper 52. Dhaka: International Centre for Diarrhoeal Disease Research, Bangladesh.

Kodjogbe, Nicaise, Gora Mboup, Justin Tossou, Leopoldine de Souza, Timothee Gandaho, Alphonse Guedeme, Thomas Houedokoho, Rafatou Houndekon, Thomas Tohouegnon, Suzanne Zomahoun, Virgile Capo-Chichi, and Andree Cossi. 1997. Benin Demographic and Health Survey, 1996. Calverton, MD: Institut National de la Statistique et de l'Analyse Economique and Macro International. 
Kols, Adrienne J. and Maria J. Wawer. 1982. "Community-based Health and Family Planning." Population Reports Series L, Number 3.

Kritz, Marcy M. and Douglas T. Gurak. 1989. "Women's status, education and family formation in sub-Saharan Africa." International Family Planning Perspectives 15(3): 100-105.

Kuseka, Innocent, Terry Silberman, Adrienne Kols, and Cheryl L. Lettenmaier. 1990. "Male Motivation Impact Evaluation Survey." Harare, Zimbabwe: Zimbabwe National Family Planning Council, Evaluation and Research Unit. Unpublished.

Kuwana, B. 1989. "Differences in functioning of an urban and a rural program (The case of Nsona Mpangu and Matadi). In Proceedings of a Conference Held at Palais du Peuple, Kinshasa, Zaire, 19-21 July, 1989. Kinshasa: Le Projet des Services des Naissances Désirables and Tulane University. Pp. 17-20.

Kwansa, Ernest. 1990. "Reaching men: The Ghanaian experience." In Family Planning for Life: Experiences and Challenges for the 1990's, ed. Mohammed Bouzidi and Rolf Korte. London: International Planned Parenthood Federation. Pp. 129-142.

Kwara State Ministry of Health. 1990. "Ilorin Market-Based Distribution Project: Final Report." Report of an operations research project of the Kwara State Ministry of Health to the Center for Population and Family Health, Columbia University and the United States Agency for International Development.

Labbok, Miriam H., Mark L. Jacobson, Robert L. Parker, and Farida Shah. 1985. "Implementing community health worker/family planning CBD through church health missions in Kenya: Analysis of baseline family planning data." Paper presented at the annual meeting of the American Public Health Association (APHA), Washington, DC, 17-21 November.

Labbok, Miriam H. and Farida Shah. 1988. "Operations Research Findings in Four Church Sponsored Programs in Kenya.” Occasional Paper Number 
3. Baltimore: The Johns Hopkins University School of Hygiene and Public Health Institute for International Programs.

Ladipo, O.A., Eugene Weiss, Grace Ebun Delano, J. Revson, M. Onadeko, and O. Ayeni. 1986. "Community-based distribution on low-cost family planning and maternal and child health services in rural Nigeria." In Health and Family Planning in Community-Based Distribution Programs, ed. Maria Wawer, Sandra Huffman, Deborah Cebula, and Richard Osborn. Boulder, CO: Westview Press. Pp. 371-381.

Ladipo, O.A., Regina McNamara, Grace Ebun Delano, Eugene Weiss, and E.O. Otolorin. 1990. "Family planning in traditional markets in Nigeria." Studies in Family Planning 21(6): 311-321.

Lagos Study Team. 1986. "The Market Women Contraceptive Survey: Second Phase." Final report submitted to the Society for Family Health, Lagos, Nigeria. Unpublished.

Lambo, E., T. Adewoye, K Adeyemi, and T. Okorosobo. 1990. "Ilorin Marketbased Distribution Project Report." Report of the Department of Management Sciences, University of Ilorin, Ilorin, Nigeria to the Kwara State Ministry of Health and the Columbia University Center for Population and Family Health, New York. Unpublished.

Lauro, Donald 1987. "Sudan community-based family health project." In Proceedings: A Conference on Community-Based Distribution and Alternative Delivery Systems in Africa: Harare, Zimbabwe, 3-7 November, 1986. Washington, DC: American Public Health Association.

Lauro, Donald, Regina McNamara, Maria Wawer, and Catherine Maternowska. 1991. "Demonstrating demand for family planning: Creating a supportive environment through operations research." In Operations Research: Helping Family Planning Programs Work Better, ed. Myrna Seidman and Marjorie C. Horn. New York: Wiley-Liss.

Lawrence, Paul R. and Jay W. Lorsch. 1969. Developing Organizations: Diagnosis and Action. Reading, MA: Addison-Wesley Publishing Company. 
Legemate, C., P. Blignaut, N. van Velden, W. Wertlen, S. van Niekerk, M. Theron, S. van Wyk, J. Peattie, A. van Schalkwyk, and J. Pattison-Bacon. 1996. “A community-based strategy for family planning." South African Medical Journal 86(11): 1,386-1,388.

Leonard, David K. 1977. Reaching the Peasant Farmer: Organization Theory and Practice in Kenya. Chicago: The University of Chicago Press.

Lerman, Charles, John W. Molyneaux, Soetedjo Moeljodihardjo, and Sahala Pandjaitan. 1989. "The correlation between family planning program inputs and contraceptive use in Indonesia." Studies in Family Planning 20(1): 26-37.

Lesthaeghe, Ronald J. 1989. Reproduction and Social Organization in Sub-Saharan Africa. Berkeley: University of California Press.

Lewis, Gary L., Margaret Watani, Polly Mott, Vane Nyong'a, and Molly Gingerich. 1991. "An assessment of the Saradidi Rural Health Project.” Nairobi: Centre for African Family Studies. Unpublished.

Lewis, Gary L., Nelson A. Keyonzo, and Polly Mott. 1992. "Community-based family planning services: Insights from the Kenyan experience." Paper presented at the annual meeting of the Population Association of America, Denver, CO, 28 April- 2 May.

Luck, Margaret, M. Diane Nell, Ebrima Jarjou, and Marc Michaelson. 1996. "Contributions of demand mobilization and contraceptive availability to increased contraceptive prevalence: Issues for replication." Final report. Save the Children Federation, the Gambia Field Office. Unpublished.

Maendeleyo ya Wanawake Organization. 1991. "Maendeleyo ya Wanawake integrated MCH/CBD family planning project programmatic outputs from July, 1990 to March, 1991.” Nairobi: Pathfinder International and Maendeleyo ya Wanawake. Unpublished.

Maine, Deborah. 1981. Family Planning: Its Impact on the Health of Women and Children. New York: Columbia University School of Public Health Center for Population and Family Health. 
Makindu, E.R. 1987. “The Maendeleyo ya Wanawake Programme of community-based distribution of contraceptives." In Proceedings: A Conference on Community-Based Distribution and Alternative Delivery Systems in Africa: Harare, Zimbabwe, 3-7 November, 1986. Washington, DC: American Public Health Association.

Makomva, R., S. Falala, and T. Johnston. 1991. "Fertility-related, husband wife communication in Zimbabwe: An indicative qualitative analysis." In African Research Studies in Population Information, Education and Communication, ed. T. Johnston, A. de Zeeuw, and W. Gikonyo. Nairobi, Kenya: United Nations Population Fund. Pp.1-12.

Malawi National Statistics Office and Macro International. 1997. Malawi Knowledge, Attitudes and Practices in Health Survey, 1996. Malawi: National Statistical Office.

Masha, A. 1987. "Marketing to market women in Nigeria." In Proceedings: A Conference on Community-Based Distribution and Alternative Delivery Systems in Africa: Harare, Zimbabwe, 3-7 November, 1986. Washington, DC: American Public Health Association.

Mauldin, W. Parker and Robert J. Lapham. 1987. "The measurement of family planning inputs." In Organizing for Effective Family Planning Programs, ed. Robert J. Lapham and George B. Simmons. Washington, DC: National Academy Press.

Mboup, Gora and Prosper Poukouta. 1995. "Availability of community services." In Enquête Démographique et de Santé, République Centrafricaine, 199495, ed. R. Ndamobissi, G. Mboup, and E.O. Nguelebe. Central African Republic: Division des Statistiques et des Etudes Economiques.

McCharen, Nancy, Michel Pacque, and Attaher Toure. 1997. Mali Child Survival Activities to Incorporate into the CBD System on a Trial Basis. Washington, DC: BASICS.

McGinn, Therese. 1989. "Accelerating family planning acceptance in Rwanda: Results of an operations research project." Paper presented at the 117th 
annual meeting of the American Public Health Association, Chicago, 2226 October.

McGuire, Elizabeth S. 1984. "Family planning operations research: A decade of experience." Paper prepared for the NCIH 11th Annual International Health Conference, Washington, DC.

McNamara, Regina. 1985. Birth Intervals and Mortality in Infancy and Childhood. Columbia University. $\mathrm{PhD}$ dissertation.

McNamara, Regina, Therese McGinn, Donald Lauro, and John A. Ross. 1992. Family Planning Programs in Sub-Saharan Africa: Case Studies from Ghana, Rwanda, and the Sudan. Washington, DC: Population and Human Resources Department, The World Bank, WPS 1004.

McNamara, Regina, O.A. Ladipo, Grace E. Delano, and Eugene Weiss. 1990. "The Ibadan market-based distribution project: partnership for primary health care and family planning." Paper presented at the National Council for International Health, Arlington, VA.

Meekers, Dominique. 1997. "The Implications of Free and Commercial Distribution for Condom Use: Evidence from Cameroon." PSI Research Division Working Paper No. 9. Washington, DC: Population Services International.

Mhloyi, Marvellous M. 1991. "Fertility transition in Zimbabwe.” Paper presented at the International Union for the Scientific Study of Population Committee on Comparative Analysis of Fertility and University of Zimbabwe Seminar on the Course of Fertility Transition in Sub-Saharan Africa, Harare, Zimbabwe, 19-22 November. Unpublished.

Ministry of Health, Health Research Unit. 1991a. "First make sure our children won't die: An appraisal of community potential to support family planning services in Bolgatanga District." Accra, Ghana: Ministry of Health, Health Research Unit.

1991b. "Won't it cause infertility?: An appraisal of community potential 
to support family planning services in Berekum District." Accra, Ghana: Ministry of Health, Health Research Unit.

- 1991c. "The ability to keep secrets: An appraisal of community potential to support family planning services in Dangbe West District." Accra, Ghana: Ministry of Health, Health Research Unit.

1992. "Conception and Misconceptions: Community Views of Family Planning." Accra, Ghana: Ministry of Health, Health Research Unit.

Morton, A.L. 1989. "Report of a revisit to an operations research project in Rwanda, September 12-23, 1989.” Washington, DC: TvT Associates, Maximizing Results of Operations Research Project.

Motlomelo, S., T. Maliehe, M. Skoane, and Gary Lewis. 1990. "Report on the Lesotho Planned Parenthood Association community-based distribution project evaluation.” Maseru, Lesotho: S. Lesotho Distance Teaching Center, etsi Sa Tsoelopele Thutong.

Mugwagwa, N.O. 1989. "Evolution and growth of family planning in Zimbabwe." In Developments in Family Planning Policies and Programmes in Africa. Legon, Ghana: University of Ghana, Regional Institute for Population Studies. Pp. 523-47.

Mukaire, Joy, Florence Kalikwani, Baker Ndugga Maggwa, and Wilson Kisubi. 1997. "Integration of STI and HIV/AIDS services with MCH-FP services: A case study of the Busoga Diocese Family Life Education Program, Uganda." New York: The Population Council Operations Research and Technical Assistance Africa Project.

Mukolwe, Jennifer J.N., John Kekovole, and Nelson A. Keyonzo. 1990. Best Practice Project Study: The Family Planning Association of Kenya Community Based Distribution Project: Major Findings. Unpublished.

Mundy, Jackie and Ian Askew. 1994. "Current experiences with community-based distribution of family planning in Kenya: A review prepared for USAID/ 
Kenya." Nairobi, Kenya: The Africa Operations Research and Technical Assistance Project II, The Population Council.

Munyakazi, A. 1989. "L'experience des abakangurambaga en communes Gatonde et Kihado de la préfecture Ruhengeri." Imborezamuryango, Office National de la Population, Rwanda No. 15, August: 14-20.

Musau, S.N. 1997. "Family Life Education Project, Busoga Diocese, Uganda: Cost analysis report, January 1997.” Arlington, VA: Partnership for Child Health Care, BASICS.

Muvandi, Ityai. 1990. "Utilization of research findings for the improvement of family planning programmes: Implications for IE and C." Harare, Zimbabwe: Zimbabwe National Family Planning Council, Evaluation and Research Unit.

National Council on Women and Development. 1990. "Accra market operations research project: Final report." Report to the Operations Research Program, Center for Population and Family Health, School of Public Health, Columbia University. Accra, Ghana: National Council of Women and Development, National Secretariat and Greater Accra Regional Secretariat. Unpublished.

National Research Council. 1993. Factors Affecting Contraceptive Use in SubSaharan Africa. Washington, DC: National Academy Press.

Nazzar, Alex, Philip B. Adongo, Fred N. Binka, James F. Phillips, and Cornelius Debpuur. 1995. "Developing a culturally appropriate family planning program for the Navrongo experiment." Studies in Family Planning 26(6): 307-324.

Ndeti, Cecilia, Lewis Ndhlovu, and P. Kumalo. 1990. "Family Life Association of Swaziland: CBD Pilot Project Evaluation Report." Nairobi: The Population Council and Swaziland: Ministry of Health.

Neuvians, Dieter. 1989. Deutsche Gesellschaft für Technische Zusammenarbeit (GTZ). Personal communication. 
Nicholas, David D. 1978. “The Danfa family planning program.” Paper presented at the 106th annual meeting of the American Public Health Association, Los Angeles, CA, 16 October.

Njogu, Wamucii. 1991. "Contraceptive use in Kenya: Trends and determinants." Demography 28(1): 83-99.

Nzuma, T. 1987. "Community-based distribution/alternative delivery systems programme in Zimbabwe.” In Proceedings: A Conference on Community-Based Distribution and Alternative Delivery Systems in Africa: Harare, Zimbabwe, 3-7 November, 1986. Washington, DC: American Public Health Association.

Office National de la Population (ONAPO) and Columbia University, Center for Population Family Health. 1989. Rapport de l'Etude sur la Promotion et la Préstation des Service de Planification Familiale à Base Communautaire à Ruhengeri Rwanda. Kigali: ONAPO.

Oliver, Roland Anthony. 1992. The African Experience: Major Themes in African History from Earliest Times to the Present. New York: Icon Editions of Harper-Collins.

Osborn, Richard W. and William A. Reinke, (eds.). 1981. Community Based Distribution of Contraception: A Review of Field Experience. Baltimore: Johns Hopkins Population Center, The Johns Hopkins University, School of Hygiene and Public Health.

Pathfinder International. 1998. 1998 Annual Report. Watertown, MA: Pathfinder International.

Penn, C. 1989. "Reaching out in Gambia." IPPF Review of Population and Development: People 16(4): 36-37.

Perrow, Charles. 1970. Organizational Analysis: A Sociological View. London: Tavistock Publications.

Peters de Folch Lyon, E. 1985. "Ibadan market women CBD project motivational research (focus group research)." Report to the Ibadan Market-Based Health and Family Planning Project. Unpublished. 
Phillips, James F., Frank Kubaze Adazu, Martin Adjuik, and Alex Nazzar. 1998. "Survey research on reproductive preferences and contraceptive use in traditional Africa: Are the responses meaningful?” Unpublished.

Phillips, James F. and Wendy Greene. 1993. "Community Based Distribution of Family Planning in Africa: Lessons from Operations Research.” New York: The Population Council, Africa Operations Research and Technical Assistance Project.

Phillips, James F., Daniel Kabira, and Gary L. Lewis. 1992. "Strategies for the community-based distribution of contraceptives in the Kenyan family planning program." Report prepared for the Africa Operations Research and Technical Assistance Project. Unpublished.

Population Concern. 1997. 1996 Annual Report. London: Population Concern.

Population Council and Africa Operations Research and Technical Assistance Project II. 1997. "An innovative approach to providing reproductive health services at the community level in Burkina Faso." Update 8: 1-4.

Population Council and Institute for Resource Development. 1991. "Zimbabwe 1988: Results from The Demographic and Health Survey." Studies in Family Planning 22(6): 395-399.

Population Reference Bureau. 1987. Making Community Based Distribution Work. Washington, DC: Population Reference Bureau.

Population Services International. 1996a. "Social marketing for family planning." www.psiwash.org/family.htm.

1996b. "PSI spearheads nationwide family planning partnership in Guinea." PSI Profile April:1-4.

Primary Health Care Directorate, Oyo State Ministry of Health, Nigeria and Operations Research Program, Center for Population and Family Health, School of Public Health, Columbia University, New York. 1989. Oyo State Community-Based Distribution Program Operations Research Project: Final Report, October 1989. Unpublished. 
Pritchett, Lant H. 1994. "Desired fertility and the impact of population policies." Population and Development Review 20(1): 1-55.

Projet des Services des Naissances Désirables and The Population Council Africa Operations Research and Technical Assistance Project (OR/TA). 1991. "A situation analysis of the family planning program of Zaire: A comparison of three service delivery systems." Kinshasa: Projet des Services des Naissances Désirables.

Projet des Services des Naissances Désirables and Tulane University. 1989. "Résumé conference sur les resultats des recherces opérationnelles en naissances désirables au Zaire.” Unpublished.

_. 1993. "Incorporating IEC activities for AIDS into a contraceptive community-based distribution (CBD) project in Kinshasa." In Operations Research Family Planning Database Project Summaries. New York: The Population Council.

Robey, Bryant, John Ross, and Indu Bhushan. 1996. "Meeting Unmet Need: New Strategies.” Population Reports Series J, Number 43.

Rogers, Everett M. 1973. Communication Strategies for Family Planning. New York: Free Press.

1995. Diffusion of Innovations, fourth edition. New York: Free Press.

Rogers, Everett M. and F. Floyd Shoemaker. 1971. Communication of Innovations: A Cross Cultural Approach. New York: Free Press.

Rosenfield, Allan G. 1977. "Medical supervision for contraception: Too little or too much?" American Journal of Obstetrics and Gynecology 115(2): 105110 .

— 1987. "The medical rationale for CBD strategies." In Proceedings: A Conference on Community-Based Distribution and Alternative Delivery Systems in Africa: Harare, Zimbabwe, 3-7 November, 1986. Washington, DC: American Public Health Association. 
Rosenfield, Allan G. and Charoon Limcharoen. 1972. "Auxiliary midwife prescription of oral contraceptives." American Journal of Obstetrics and Gynecology 114: 942-949.

Rosenfield, Allan G., Chitt Hemachudna, Winich Asavasena, and Somsak Varakamin. 1971. “Thailand: Family planning activities 1968-70.” Studies in Family Planning 2(9): 181-192.

Ross, John A. 1990. "Family planning pilot projects.” In Population Growth and Reproduction in Sub-Saharan Africa: Technical Analyses of Fertility and its Consequences, ed. George T.F. Acsadi, Gwendolyn Johnson-Acsadi, and Rodolfo A. Bulatao. Washington, DC: The World Bank.

Ross, John A., Donald J. Lauro, Joseph D. Wray, and Allan G. Rosenfield. 1987. "Community based distribution." In Organizing for Effective Family Planning Programs, ed. Robert J. Lapham and George B. Simmons. Washington, DC: National Academy Press.

Ross, John A., W. Parker Mauldin, Steven Green, and Romana Cooke. 1992. Family Planning and Child Survival Programs as Assessed in 1991. New York: The Population Council.

Ross, John A. and Elizabeth Frankenberg. 1993. Findings from Two Decades of Family Planning Research. New York: The Population Council.

Rukuongwe, A. 1987. "Community-based distribution pilot project in Tanzania." In Proceedings: A Conference on Community-Based Distribution and Alternative Delivery Systems in Africa: Harare, Zimbabwe, 3-7 November, 1986. Washington, DC: American Public Health Association.

Schuler, Sidney, Syed M. Hashemi, Ann Riley, and S. Akhter. 1996. "Credit programs, patriarchy and men's violence against women in rural Bangladesh." Social Science and Medicine 43(12): 1,729-1,742.

Seewald, D. 1990. "The community health movement started from a simple program." Integration 26: 4-7. 
Sherris, Jacqueline D., Betty Butler Ravenholt, and Richard Blackburn. 1985. "Family Planning Programs." Population Reports Series J, Number 30, pp. 773-812.

Simmons, George B. 1992. "Supply and demand, not supply versus demand: Appropriate theory for the study of the effects of family planning programmes on fertility." In Family Planning Programmes and Fertility, ed. James F. Phillips and John A. Ross. Oxford: Clarendon Press.

Simmons, Ruth and Ann M. Young. 1996. "Family planning programs and other interventions to assist women: Their impact on demographic change and on the status of women." Honolulu and New York: East-West Center and Rockefeller Foundation.

Simmons, Ruth, Peter Hall, Juan Díaz, Margarita Díaz, Peter Fajans, and Jay Satia. 1997. "The strategic approach to contraceptive introduction." Studies in Family Planning 28(2): 79-94.

Simmons, Ruth, Rezina Mita, and Michael A. Koenig. 1992. "Employment in family planning and women's status in Bangladesh." Studies in Family Planning 23(2): 97-109.

Simmons, Ruth, Laila Baqee, Michael A. Koenig, and James F. Phillips. 1988. "Beyond supply: The importance of female family planning workers in rural Bangladesh.” Studies in Family Planning 19(1): 29-38.

Sinding, Stephen W., John A. Ross, and Allan G. Rosenfield. 1993. "Seeking common ground: Unmet need and demographic goals." Unpublished.

Society for Family Health. 1997a. "Operation REACH.” Social Marketing Update 1(4): 3.

- 1997b. "Social marketing: playing an important role in public health." Social Marketing Update 1(4): 3.

Sowa, Nii K. and Patrick O. Ohadike. 1989. "Economic constraints in family planning and contraceptive use in Africa." In Developments in Family Plan- 
ning Policies and Programmes in Africa. Legon, Ghana: University of Ghana, Regional Institute for Population Studies.

Supe, G. and D. Blankhart. 1996. "Reaching youth in the Central African Republic.” AIDS/STD Health Promotion Exchange (3): 3-6.

Tanzania Bureau of Statistics and Macro International. 1997. Tanzania Demographic and Health Survey, 1996. Tanzania: Bureau of Statistics.

Taylor, W. E. 1996. “Initiatives: Sierra Leone.” Africa Link April: 10-11.

Townsend, John W. 1991. "Effective family planning service components: Global lessons from operations research." In Operations Research: Helping Family Planning Programs Work Better, ed. Myrna Seidman and Marjorie C. Horn. New York: Wiley-Liss.

Turner, R. 1991. "Most Zimbabwean men approve of family planning, but believe it should wait until after the first birth." International Family Planning Perspectives 17(3): 115-116.

Twaha, A., G. J. Ebrahim, G.C.J. Vogel, and Erik van Praag. 1989. "Lessons for national health systems from small-scale projects: A case study from Tanzania." Journal of Tropical Pediatrics 35: 40-43.

United Nations. 1993. World Population Prospects. New York: The United Nations Department for Economic and Social Information and Policy Analysis.

. 1998. World Urbanization Prospects: The 1996 Revision: Estimates and Projections of Urban and Rural Populations and of Urban Agglomerations. New York: United Nations Population Division, Department of Economic and Social Affairs.

University of Ghana Medical School. 1979. "The Danfa Comprehensive Rural Health and Family Planning Project: Summary, conclusions, and recommendations from the final report." Accra, Ghana: University of Ghana Medical School. 
van de Walle, Etienne and Andrew D. Foster. 1990. "Fertility Decline in Africa: Assessment and Prospects." World Bank Technical Paper Number 125, Africa Technical Department Series. Washington, DC: The World Bank.

van de Walle, Francine, and Kehinde Omideyi. 1988. "The cultural roots of African fertility regimes.” In African Population Conference, Dakar, Senegal, International Union for the Scientific Study of Population, pp. 2.2.352.2.53.

Warwick, Donald P. 1988. "Culture and the management of family planning programs.” Studies in Family Planning 19(1): 1-18.

Warwick, Donald P. et al. 1983. "The Indonesian Family Planning Program.” Development Program Implementation Study Report Number 3. Jakarta: Harvard Institute for International Development.

Webb, Glenn. 1987a. "Observation research among Ibadan market CBD agents: A report on research conducted for the Fertility Research Unit, College of Medicine, University of Ibadan." Report to the Ibadan Market-Based Health and Family Planning Project. Unpublished.

_ 1987b. "Market associations and the Ibadan Market-Based Health Project." Paper presented at the Workshop on Market-Based Distribution of Health and Family Planning Services, Ibadan, Nigeria, 18-22 May.

- 1988. "A comparative analysis of relatively successful and unsuccessful Ibadan market agents." Report to the Ibadan Market-Based Health and Family Planning Project. Unpublished.

- 1989. "Mini-survey of trader and shopper awareness, purchases, and attitudes regarding the Ibadan Market-Based Health and Family Planning Project." Report on research conducted for the Fertility Research Unit, College of Medicine, University of Ibadan. Unpublished.

Weiss, Eugene 1985. "Operations research in health and family planning services: Lessons to be learned from the Oyo State Project." In Conference on 
the Oyo State CBD Project: Community-Based Delivery of Health and Family Planning Services. Ibadan: University College Hospital, Fertility Research Unit and Ministry of Health and New York: Center for Population and Family Health, Columbia University.

- 1998. "Evaluation of CEDPA's ACCESS Project in Nigeria: Community-Based Distribution (CBD) Programs." Unpublished.

Wilkinson, Marilyn I. 1992. The Relationship of Service Provision to Contraceptive Use in Zimbabwe. Baltimore: School of Hygiene and Public Health of The Johns Hopkins University. PhD dissertation.

Wilkinson, Marilyn I., Noureddine Adberrahim, and Wamucii Njogu. 1991. "Availability and use of contraception: A comparative analysis." In Demographic and Health Surveys World Conference Proceedings, volume 2. IRD/Macro International. Pp. 1,255-1,272.

Wolf, Edward C. 1986. "Beyond the Green Revolution: New Approaches for Third World Agriculture." Worldwatch Paper 73. Washington, DC: Worldwatch Institute.

Wolff, James A., Robert Cushman, Florida A. Kweekeh, C. Elizabeth McGrory, and Susanna C. Binzen. 1990. Beyond the Clinic Walls. West Hartford, CT: Kumarian Press.

World Health Organization. 1986a. "Provision by non-physicians of family planning care in rural areas of Egypt." WHO Special Programme of Research, Development and Research Training in Human Reproduction. Unpublished.

_ 1986b. "Provision by non-physicians of family planning care in the rural Philippines." WHO Special Programme of Research, Development and Research Training in Human Reproduction. Unpublished.

1986c. "Provision by non-physicians of family planning care in Cubuk District, Turkey." WHO Special Programme of Research, Development and Research Training in Human Reproduction. Unpublished. 
- 1986d. "The non-physicians provision of clinical family planning in Seoul, Korea.” WHO Special Programme of Research, Development and Research Training in Human Reproduction. Unpublished.

- 1989. WHO Guidelines on Community-Based Distribution of Contraceptives in Family Planning Programmes (draft). Unpublished.

Wortman, Judith. 1975. "Training Non-physicians in Family Planning Services." Population Reports Series J, Number 6.

Wulf, Deirdre. 1985. "The future of family planning in sub-Saharan Africa." International Family Planning Perspectives 11(1): 1-8.

Zimbabwe Central Statistical Office and Macro International. 1995. Zimbabwe Demographic and Health Survey, 1994. Harare: Central Statistical Office.

Zimbabwe National Family Planning Council. 1990. The Zimbabwe Community-Based Distribution CBD Validation Study. Harare, Zimbabwe: National Family Planning Council, Evaluation and Research Unit.

Zinanga, Alex. 1990. "Community-based distribution programmes in Zimbabwe." In Family Planning for Life: Experiences and Challenges for the 1990s, ed. Mohammed Bouzidi and Rolf Korte. London: International Planned Parenthood Federation. Pp. 37-44.

Zurayk, Huda, Hind Khattab, Nabil Younis, Olfia Kamal, and Mahinez El-Helew. 1995. "Comparing women's reports with medical diagnoses of reproductive morbidity conditions in rural Egypt." Studies in Family Planning 26(1): 14-21. 


\title{
POLICY RESEARCH DIVISION WORKING PAPERS
}

\author{
Recent Back Issues
}

\section{7}

93 James F. Phillips, Fred N. Binka, Martin Adjuik, Alex Nazzar, and Kubaze Frank Adazu, "The determinants of contraceptive innovation: A case-control study of family planning acceptance in a traditional African society."

94 John Bongaarts and Sajeda Amin, "Prospects for fertility decline and implications for population growth in South Asia."

95 Barbara S. Mensch and Cynthia B. Lloyd, "Gender differences in the schooling experiences of adolescents in low-income countries: The case of Kenya."

96 Martin Brockerhoff and Ellen Brennan, "The poverty of cities in the developing world."

97 Carol E. Kaufman, "Reproductive control in South Africa."

98 John Bongaarts, "Trends in unwanted childbearing in the developing world."

99 Mary Arends-Kuenning, "How do family planning workers' visits affect wom- en's contraceptive behavior in Bangladesh?"

100 Mark R. Montgomery and Cynthia B. Lloyd, "Excess fertility, unintended births, and children's schooling."

101 Mary Arends-Kuenning, "The equity and efficiency of doorstep delivery of contraceptives in Bangladesh."

102 Sajeda Amin, Ian Diamond, Ruchira T. Naved, and Margaret Newby, "Transition to adulthood of female factory workers: Some evidence from Bangladesh."

*103 Margaret E. Greene and Ann E. Biddlecom, "Absent and problematic men: Demographic accounts of male reproductive roles."

104 Michael P. Todaro, "Urbanization, unemployment, and migration in Africa: Theory and policy."

105 Geoffrey McNicoll, "Population and poverty: A review and restatement."

\footnotetext{
* No longer available
} 
106 Sajeda Amin and Gilda Sedgh, "Incentive schemes for school attendance in rural Bangladesh."

107 Martin Brockerhoff and Paul Hewett, "Ethnicity and child mortality in subSaharan Africa."

108 Ann E. Biddlecom and Bolaji M. Fapohunda, "Covert contraceptive use: Prevalence, motivations, and consequences."

109 John Bongaarts and Griffith Feeney, "On the quantum and tempo of fertility."

110 Barbara S. Mensch, Daniel Bagah, Wesley H. Clark, and Fred Binka, "The changing social environment for adolescents in the Kassena-Nankana District of northern Ghana: Implications for reproductive behavior."

111 Martin Brockerhoff and Ann Biddlecom, "Migration, sexual behavior, and HIV diffusion in Kenya."

112 Zeba A. Sathar and John B. Casterline, "The onset of fertility transition in Pakistan."

113 Geoffrey McNicoll, "Government and fertility in transitional and post-transitional societies."
114 John Bongaarts, "Fertility and reproductive preferences in post-transitional societies."

115 Fiona Steele, Sajeda Amin, and Ruchira T. Naved, "The impact of an integrated micro-credit program on women's empowerment and fertility behavior in rural Bangladesh."

116 Cynthia B. Lloyd, Barbara S. Mensch, and Wesley H. Clark, "The effects of primary school quality on the educational participation and attainment of Kenyan girls and boys."

117 Sajeda Amin and Cynthia B. Lloyd, "Women's lives and rapid fertility decline: Some lessons from Bangladesh and Egypt."

118 James F. Phillips and Mian Bazle Hossain, "The impact of family planning household service delivery on women's status in Bangladesh."

119 Mark R. Montgomery and John B. Casterline, "Social networks and the diffusion of fertility control."
120 John Bongaarts, "The fertility impact of changes in the timing of childbearing in the developing world."
121 James F. Phillips, Wendy L. Greene, and Elizabeth F. Jackson, "Lessons from community-based distribution of family planning in Africa." 